\title{
Forecast Advisory for a Cold-Season Heavy Rainfall/Flood Event That Developed from Multiple Interactions of the Cold-Surge Vortex with Cold-Surge Flows in the South China Sea ${ }^{\mathscr{O}}$
}

\author{
TSING-CHANG CHEN AND JENQ-DAR TSAY \\ Department of Geological and Atmospheric Sciences, Iowa State University, Ames, Iowa \\ Jun MATSUMoto \\ Department of Geography, Tokyo Metropolitan University, Tokyo, and Department of Coupled \\ Ocean-Atmosphere-Land Processes Research, JAMSTEC, Yokosuka, Japan \\ JORDAN ALPERT \\ National Centers for Environmental Predication/Environmental Modeling Center, College Park, Maryland
}

(Manuscript received 16 August 2016, in final form 17 January 2017)

\begin{abstract}
The peak intensity occurrence frequency over the life cycles of parent cold-surge vortices (CSVs) for heavy rainfall/flood (HRF) events is classified into two types depending on their life cycles having two or three peak intensities, denoted as $\mathrm{HRF}^{2}$ or $\mathrm{HRF}^{3}$, respectively. The formation of an $\mathrm{HRF}^{2}$ event from its parent $\operatorname{CSV}\left(\mathrm{HRF}^{2}\right)$ formation is $\leq 5$ days, while the formation of an $\mathrm{HRF}^{3}$ event is $\geq 6$ days. The latter group contributes $\sim 57 \%$ of the total number of HRF events. As a result of some model constraints, the formation and development of $\mathrm{HRF}^{3}$ events are not well forecasted by the Global Forecast System (GFS) and regional forecast models. The life cycle and second peak intensity for $\operatorname{CSV}\left(\mathrm{HRF}^{3}\right)$ allow for the introduction of a forecast advisory for $\mathrm{HRF}^{3}$ events. Identification of CSVs and two sufficient requirements for the formation and occurrence of HRF events were developed by previous studies. Nevertheless, two new necessary steps are now included in the proposed forecast advisory. The population ratio for $\mathrm{CSV}\left(\mathrm{HRF}^{3}\right)$ and the regular CSV is only about $15 \%$. The occurrence optimum time $t_{o}$ for the $\operatorname{CSV}\left(\mathrm{HRF}^{3}\right)$ second peak intensity from this vortex formation is about 3 days $6 \mathrm{~h}$. The GFS forecast over $t_{o}$ is utilized to identify $\operatorname{CSV}\left(\mathrm{HRF}^{3}\right)$. Then, the relay of the GFS forecast from the occurrence time of the $\operatorname{CSV}\left(\mathrm{HRF}^{3}\right)$ second peak is used to predict the formation/ occurrence of $\mathrm{HRF}^{3}$ events. Six $\mathrm{HRF}^{3}$ events during cold seasons for 2013-16 are used to test the feasibility of this forecast advisory. Results clearly demonstrate this advisory is a success for the forecast of $\mathrm{HRF}^{3}$ events over the entire life cycles of their parent $\operatorname{CSV}\left(\mathrm{HRF}^{3}\right) \mathrm{s}$.
\end{abstract}

\section{Introduction}

The most hazardous weather in winter around the South China Sea (SCS) is from heavy rainfall/flood (HRF) events, for example, the 2008 Hanoi event (31 October 2008) in north Vietnam (BBC 2008), the 2008 Kuantan event (29 November 2008) in the Malaysian Peninsula

Supplemental information related to this paper is available at the Journals Online website: http://dx.doi.org/10.1175/ WAF-D-16-0148.s1.

Corresponding author e-mail: Tsing-Chang (Mike) Chen, tmchen@ iastate.edu
(Reliefweb 2009), and many others. Accurate forecasts for HRF events are important for the life, property, and commerce of Southeast Asians living around the SCS. To test the effect of local topography on the rainfall distribution of an HRF event over the east coast of Peninsular Malaysia, Juneng et al. (2007) used the fifth-generation Pennsylvania State University-NCAR Mesoscale Model (MM5) to make 4-day forecasts for an HRF event (9-11 December 2004). The life cycle of this event, beginning from the formation of a cold-surge vortex (CSV) and its development into an HRF event in Borneo, is 7 days (4-10 December 2004). Using Colorado State University's Regional Atmospheric Modeling System (Cotton et al. 2003), Truong et al. (2009) tested the impact 
of different parameterization schemes on the 2-day precipitation forecast of an HRF event in central Vietnam (24-26 November 2004). The life cycle for this HRF event is 6 days from its parent CSV that formed in the vicinity of the Philippines. Application of regional forecast models to predict the occurrence of HRF events over regions around the SCS faces two constraints: 1) the limited domain may reduce the ability to accurately depict the extratropical-tropical and global/hemispheric-regional interactions of the weather systems of interest and 2) the limited forecast time may reduce the forecastability for the long-duration development from the CSV formation to the occurrence of the HRF event.

Shown in Fig. 1, 146 HRF events (not including the $41 \mathrm{HRF}$ events over the Philippines) are identified over 37 cold seasons (October-February) during 1979-2016. Only 11 of these HRF events that developed from formations of their parent CSVs (see Table A1 for a list of key acronyms used in this paper) have life cycles shorter than 4 days. In contrast, the other 135 HRF events, developed from their parent CSV(HRF)s, have life cycles greater than 4 days, which may exceed the time for regional forecast models to produce accurate forecasts. The National Centers of Environmental Prediction (NCEP) Global Forecast System (GFS) operationally issues 8-day forecasts (NCEP 2003). Figure 1 shows that most HRF events in central Vietnam have life cycles [from parent CSV(HRF) formations] shorter than 6 days. Utilizing the relationships of synoptic features between the extratropics and tropics, and the dynamichydrological relationships among three monsoon modes, Chen et al. (2012) introduced a forecast advisory to supplement the GFS 8-day forecast for the late fall HRF events in central Vietnam.

After their investigation of the formation mechanism driving cold-season, heavy rainfall centers over central Vietnam (Chen et al. 2012) and Malaysia (Chen et al. 2013a,b), Chen et al. (2015b) searched for the formation mechanism of parent CSV(HRF)s and their propagation properties over the entire SCS. The CSV(HRF)s form in two regions: 1) the Philippines vicinity along the island-chain surface trough and 2) the cyclonic shear region around the near-equatorial trough over Borneo. These CSV(HRF)s propagate westward (southwestward), if the westerly (northerly) component of the coldsurge flow inside the SCS is larger (smaller) than the northerly component. As shown in Fig. 1, 63 HRF events $(\sim 43 \%)$ need fewer than 5 days to develop from their parent CSV(HRF)s. In contrast, 83 HRF events $(\sim 57 \%)$ require more than 6 days to develop from the formation of their parent CSV(HRF)s. These 83 longlived CSV(HRF)s undergo a second maximum intensification through their interactions with the second cold-surge flow before the formation of their HRF events. In other words, the second peak intensity of $\mathrm{CSV}(\mathrm{HRF})$ provides a clear indication of a connection between these CSV(HRF)s with a second new coldsurge flow in the SCS. Thus, CSV(HRF)s can be classified into two groups ${ }^{1}$ :

1) The development of $\operatorname{CSV}\left(\mathrm{HRF}^{2}\right)$ into an $\mathrm{HRF}^{2}$ event that exhibits peak intensity once at the formation of $\operatorname{CSV}\left(\mathrm{HRF}^{2}\right)$ and the $\mathrm{HRF}^{2}$ event and develops in less than 5 days.

2) The development of $\operatorname{CSV}\left(\mathrm{HRF}^{3}\right)$ into an $\mathrm{HRF}^{3}$ event that undergoes a second peak intensity between formations of $\mathrm{CSV}\left(\mathrm{HRF}^{3}\right) \mathrm{s}$, and the $\mathrm{HRF}^{3}$ event is longer lived.

For convenience, we designate group 1 as $\operatorname{CSV}\left(\mathrm{HRF}^{2}\right)$ and an $\mathrm{HRF}^{2}$ event, and group 2 as $\mathrm{CSV}\left(\mathrm{HRF}^{3}\right)$ and an $\mathrm{HRF}^{3}$ event.

Chen et al. (2012) developed a forecast advisory for $\mathrm{HRF}^{2}$ events that form in central Vietnam, which can be applied to the development of $\operatorname{CSV}\left(\mathrm{HRF}^{2}\right)$ events around the SCS. However, a major concern in this study is to develop a forecast advisory for the development of $\mathrm{CSV}\left(\mathrm{HRF}^{3}\right)$ s into their $\mathrm{HRF}^{3}$ events. The longest life cycle for a $\operatorname{CSV}\left(\mathrm{HRF}^{3}\right)$ to develop into its $\mathrm{HRF}^{3}$ event is 10 days. The 16-day forecasts issued by the NCEP GFS (NWS/EMC 2016) with a resolution of $13 \mathrm{~km}$, but posted onto a $0.5^{\circ} \times 0.5^{\circ}$ grid, show the forecastability for several aspects of $\mathrm{CSV}\left(\mathrm{HRF}^{3}\right)$ characteristics, such as location, intensity, rainfall, and occurrence time of the second peak intensity. However, the forecast accuracy is reduced significantly after the first 3-5 days. It may not be feasible to use the GFS 16-day forecasts for the development or formation of $\mathrm{HRF}^{3}$ events over the entire life cycle of its parent $\operatorname{CSV}\left(\mathrm{HRF}^{3}\right)$ around the SCS. To overcome this limit of GFS forecastability, a forecast advisory is introduced to use the connection between the $\mathrm{HRF}^{3}$ event from the formation of its parent $\mathrm{CSV}\left(\mathrm{HRF}^{3}\right)$ to the second peak intensity and from this peak intensity to the formation of $\mathrm{HRF}^{3}$ events.

The feasibility of the proposed forecast advisory, referred to as relay forecasts for the entire life cycle of $\operatorname{CSV}\left(\mathrm{HRF}^{3}\right)$ to the formation of the $\mathrm{HRF}^{3}$ events, is described in the following manner. Reanalysis data generated by the NCEP GFS since 2006, by ECMWFInterim over 1979-2006, by GFS forecasts for $\mathrm{HRF}^{3}$ events since 2006, and for some special cases before 2006 are described in section 2. Observations and forecast statistics for various aspects of the $\mathrm{CSV}\left(\mathrm{HRF}^{3}\right)$ second

\footnotetext{
${ }^{1}$ An example for each group of CSV(HRF)s is shown in online supplement 1
} 


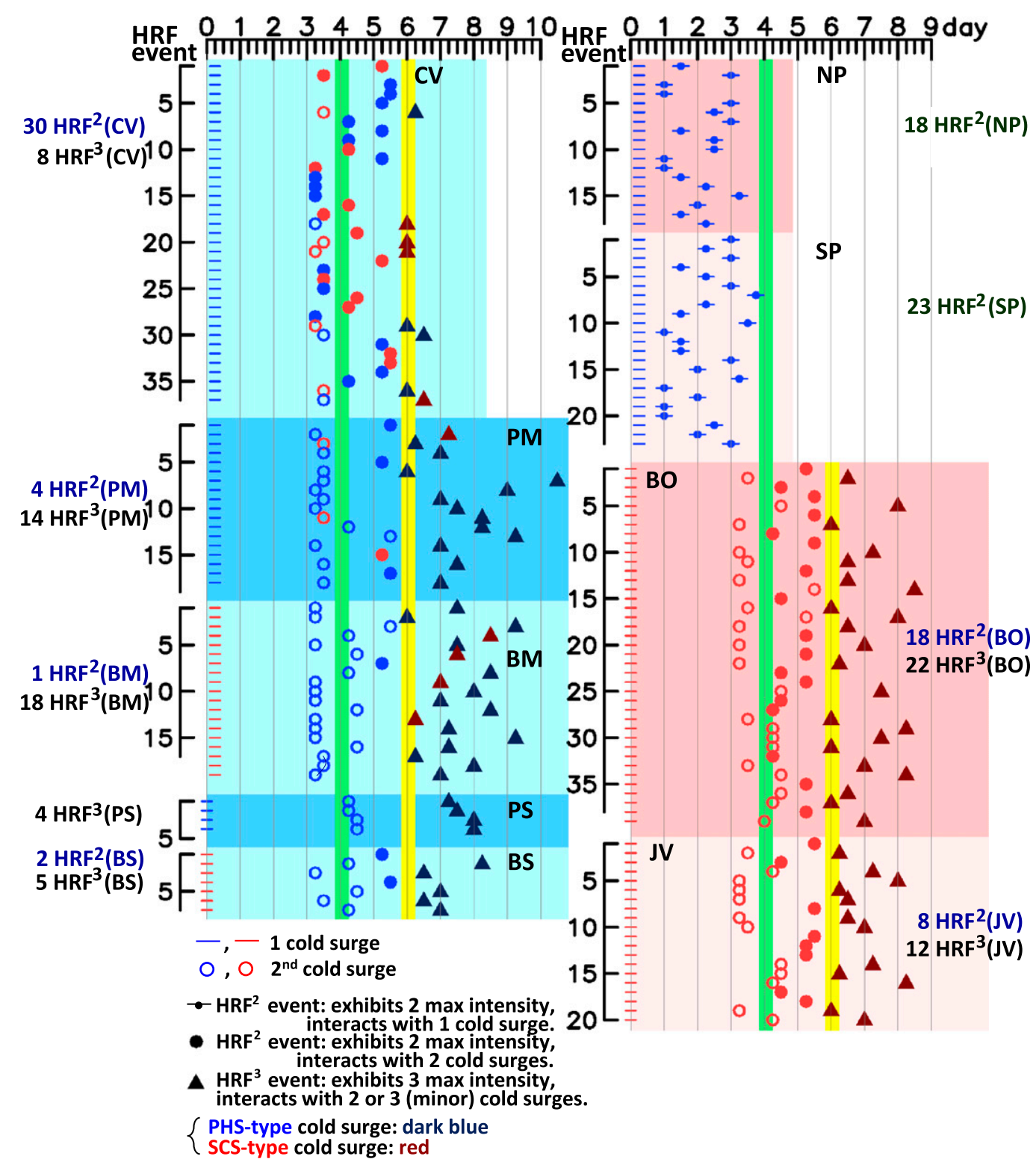

FIG. 1. The life cycle/time needed by a $\operatorname{CSV}\left(\mathrm{HRF}^{n}\right)$ to develop from its formation location and reach the formation location of the $\mathrm{HRF}^{n}$ event in seven rainfall centers, superscript $n$ is either a 2 or a 3 . Travel time is projected onto the abscissa and the case numbers of $\mathrm{HRF}^{n}$ events are scaled along the ordinate. All (187) HRF events are classified into two groups, $\mathrm{HRF}^{3}$ and $\mathrm{HRF}^{2}$, and are denoted by a solid triangle and dot, respectively. The latter group also includes $\mathrm{HRF}^{2}$ events developed from $\mathrm{CSV}\left(\mathrm{HRF}^{2}\right)$ s, which interact with only one cold-surge flow of the Philippine Sea (PHS) type, marked by a short line with a dot located at the center. An open circle denotes the second peak intensity for $\mathrm{CSV}\left(\mathrm{HRF}^{3}\right)$. The red (blue) symbol indicates the $\mathrm{CSV}\left(\mathrm{HRF}^{n}\right)$ interaction with the SCS (PHS)-type cold-surge flow. The green and yellow strips stratify the times needed to develop the second peak intensity of $\mathrm{CSV}\left(\mathrm{HRF}^{3}\right)$, and to form $\mathrm{HRF}^{2}$ and $\mathrm{HRF}^{3}$ events, respectively. Covering 37 cold seasons (1979-2016), this figure is a modified version of Chen et al.'s (2015a) Fig. 1, which includes 36 cold seasons (1979-2015).

peak intensity are presented in section 3. Results from this section for the formations of both $\operatorname{CSV}\left(\mathrm{HRF}^{3}\right) \mathrm{s}$ and their second peak intensity are compiled and utilized to develop a forecast advisory, as well as relay forecasts for the occurrence of $\mathrm{HRF}^{3}$ events. An illustration of the proposed forecast advisory for $\mathrm{HRF}^{3}$ events around the
SCS and the feasibility test for this forecast advisory are presented in section 4. A summary for relay forecasts produced by the forecast advisory for the development of $\operatorname{CSV}\left(\mathrm{HRF}^{3}\right)$ s and formation of $\mathrm{HRF}^{3}$ events, along with suggestions for future study, are offered in section 5 . 


\section{Data and identification of CSV and CSV(HRF)}

Data sources used in this study include rainfall, reanalysis, daily surface analysis maps, HRF events, and depictions of explosive cyclones. Details of these data sources are presented in Table 1 . The analysis performed with observations covers the 1979-2016 period. The data quality and amount are sufficient in terms of uniformity and abundance, a necessary condition for analysis over this $37-y r$ period. Except for rainfall, the last four data sources meet this requirement.

Two data sources (WMO stations, APHRODITE) provide information on rainfall over land, while another two data sources (TRMM, PERSIANN) furnish rainfall amounts over both land and ocean. Different periods and regions are covered by these rainfall data. To make the rainfall data uniform over the analysis region, a simple calibration procedure is adopted to prepare them. Based on the information from the rainfall datasets provided in Table 1, this procedure includes the following steps ${ }^{2}$ :

1) The TRMM rain $P($ TRMM) measurements are calibrated against the APHRODITE rainfall by determining the ratio between these two rainfall datasets over Japan, where $P($ calibrated TRMM $) \simeq$ 1.2 P(TRMM).

2) The PERSIANN rainfall is calibrated against $P$ (calibrated TRMM) for 1983-97 with $P($ calibrated PERSIANN $)=$ $1.2 \times P($ PERSIANN $)$.

3) The $P$ (calibrated TRMM) and $P$ (calibrated PERSIANN) are combined over their available period of rainfall data, as shown in Table 1 .

The major weather systems concerned in this study are CSVs, $\operatorname{CSV}\left(\mathrm{HRF}^{3}\right) \mathrm{s}, \mathrm{HRF}^{3}$ events/cyclones, and northwest Pacific (NWP) explosive cyclones. These weather systems are identified by the following approaches and data sources.

1) CSV: Two reanalysis data sources (NCEP GFS and ERA-Interim) are used to generate streamline charts. These charts, prepared with NCEP GFS analysis data, match the blackbody brightness temperature $T_{\mathrm{BB}}$ and/or rainfall distribution more closely in detail than does the ERA-Interim analysis. The GFS analysis with a $0.5^{\circ} \times 0.5^{\circ}$ resolution became available in 2006. Before this year, streamline charts were prepared with the ERA-Interim reanalysis of $0.5^{\circ} \times 0.5^{\circ}$. These streamline charts are supplemented with daily surface analysis maps

\footnotetext{
${ }^{2}$ The details involved with designing this procedure are presented in online supplement 2.
}

issued by NCEP's Service Records Retention System (SRRS), JMA, the Thai Meteorological Department (TMD), and BOM to identify the vortices of CSVs formed in the vicinity of the Philippines by the interaction of easterly waves with cold-surge flows and the island-chain troughs. Similarly, the closed vortices of CSVs are also formed over Borneo by the interaction of cold-surge flows with orography and the near-equatorial troughs across Borneo.

2) $\operatorname{CSV}\left(\mathrm{HRF}^{3}\right)$ : This type of CSV is originally formed as a CSV, but will develop into the $\mathrm{HRF}^{3}$ cyclone/ event through three peak intensities. A special approach is developed in section 3 to separate $\operatorname{CSV}\left(\mathrm{HRF}^{3}\right) \mathrm{s}$ from all identified CSVs using the GFS forecasts to check for their second peak intensity 3-5 days after they form like regular CSVs.

3) $\mathrm{HRF}^{3}$ cyclone/event: The occurrences of $\mathrm{HRF}^{3}$ events over the 1979-2016 period are identified by the Dartmouth Flood Observatory (DFO 2016) ${ }^{3}$ and the International Emerging Disaster Database (EM-DAT; CRED 2016) used in this study.

4) NWP explosive cyclone: Sanders and Gaykum (1980) identified this type of cyclone with a deepening rate of surface pressure $\leq-24 \mathrm{hPaday}^{-1}$. Observed by Chen et al. (2012), the surface pressure deepening rate of NWP explosive cyclones is underforecasted by GFS. The threshold value used to identify the NWP explosive cyclones forecasted by GFS is $\leq-15 \mathrm{hPa} \mathrm{day}^{-1}$.

\section{Development of $\mathrm{HRF}^{3}$ events and relay forecast for their occurrences}

a. Development of $H R F^{3}$ events with the second peak intensity for $\mathrm{CSV}\left(H R F^{3}\right)$

The time evolution of $\mathrm{CSV}\left(\mathrm{HRF}^{3}\right) \mathrm{s}$ with an intensity measured by the area-averaged $\zeta(925 \mathrm{hPa}) \geq$ $1.8 \times 10^{-5} \mathrm{~s}^{-1}$ over these vortices is marked by red crosses in Fig. 2a. The formation of $\mathrm{HRF}^{3}$ events undergoes three peak intensities, if the time needed for the development of their parent $\operatorname{CSV}\left(\mathrm{HRF}^{3}\right) \mathrm{s}$ is $\geq 6$ days. The first peak intensity for $\mathrm{CSV}\left(\mathrm{HRF}^{3}\right) \mathrm{s}$ occurs when they form in vicinity of the Philippines and Borneo. The second peak intensity for $\operatorname{CSV}\left(\mathrm{HRF}^{3}\right) \mathrm{s}$ occurs when these vortices interact with the second cold-surge flows over the SCS. The third peak intensity for these vortices appears when their corresponding $\mathrm{HRF}^{3}$ events develop

\footnotetext{
${ }^{3}$ Categories of $\mathrm{HRF}^{3}$ events are provided in online supplement 3 .
} 
over the cold-season rainfall centers in central Vietnam, the Malay Peninsula, Sumatra, Java, and Borneo. In Fig. 2a, the temporal evolution of CSVs is illustrated by the intensity measured following the method used for $\mathrm{CSV}\left(\mathrm{HRF}^{3}\right)$, but marked by black dots. The populations of identified CSVs and CSV $\left(\mathrm{HRF}^{3}\right)$ s feature 556 and 83 cases, respectively.

The mean intensity of CSVs depicted by the thirdorder polynomial regression line (NCAR 2016) increases to reach a peak value on day 6 , but then dissipates by day 7. In contrast, the $\operatorname{CSV}\left(\mathrm{HRF}^{3}\right)$ evolution exhibits an increasing trend to day 8 for most $\mathrm{HRF}^{3}$ events. The second peak intensity of $\operatorname{CSV}\left(\mathrm{HRF}^{3}\right) \mathrm{s}$, marked by open circles with different colors, occurs during days 3-5 (Fig. 2a). As shown in Fig. 1, the third peak intensity for $\operatorname{CSV}\left(\mathrm{HRF}^{3}\right)$, the formation of the $\mathrm{HRF}^{3}$ event marked by an open color triangle, starts to form on day 6 . They distinctly project well above the third-order polynomial regression line of the $\mathrm{CSV}\left(\mathrm{HRF}^{3}\right)$ time series. These second peak intensities are generally smaller than the third peak intensities for HRF $^{3}$ events. However, the former is an indispensable process for $\mathrm{CSV}\left(\mathrm{HRF}^{3}\right)$ s to develop into $\mathrm{HRF}^{3}$ events on day 6 and to make the intensity of $\mathrm{HRF}^{3}$ events larger than those for $\mathrm{HRF}^{2}$ events (Chen et al. 2015a). Additionally, the formation of $\mathrm{HRF}^{3}$ events needs to meet another two requirements (Chen et al. 2015a): 1) occurrence synchronization of an $\mathrm{HRF}^{3}$ event with an NWP explosive cyclone and 2) simultaneous occurrence of maximum speeds by westerlies of the $\mathrm{HRF}^{3}$ cyclone, tropical trade easterlies of the North Pacific (NP) subtropical anticyclone, and westerlies of the NWP explosive cyclone.

As observed in Chen et al. (2012), the occurrences of central Vietnam HRF events are synchronized with the formation of the majority $(\sim 2 / 3)$ of NWP explosive cyclones, which directly develop from the northeast Asian surface lows coupled with the cold-surge flows involved in the formation of their parent CSV(HRF)s. A relationship between these NWP explosive cyclones and $\mathrm{HRF}^{3}$ events is hypothesized. Figure 3 shows that 7 of the $83 \mathrm{HRF}^{3}$ events $(>8 \%)$ are synchronized with the NWP explosive cyclones that directly developed from the northeast Asian surface lows related to the formation of their parent $\mathrm{CSV}\left(\mathrm{HRF}^{3}\right)$. In contrast, 49 occurrences of $83 \mathrm{HRF}^{3}$ events $(59 \%)$ synchronize with formations of NWP explosive cyclones, which develop from the northeast Asian surface lows involved with the intensification process of the $\mathrm{CSV}\left(\mathrm{HRF}^{3}\right)$ second peak intensity. Only 27 occurrences of $83(\leq 33 \%) \mathrm{HRF}^{3}$ events synchronize with the formation of the corresponding NWP explosive cyclones developed from surface lows that originated over the leeside of the Altai Mountains northwest of Mongolia. As is shown in Fig. 3, the CSV $\left(\mathrm{HRF}^{3}\right)^{\prime}$ 's second peak intensity is not only crucial to the formation of an $\mathrm{HRF}^{3}$ event, but also is closely related to the synchronous formation of an NWP explosive cyclone with the formation of an $\mathrm{HRF}^{3}$ event.

Since 2004 and 2006, the NCEP GFS has operationally issued 8- and 16-day forecasts, respectively. For 12 cold seasons during the 2004-16 period, $30 \mathrm{CSV}\left(\mathrm{HRF}^{3}\right)$ events and 178 CSVs are identified from these GFS forecasts. We also select another five $\operatorname{CSV}\left(\mathrm{HRF}^{3}\right) \mathrm{s}$ during 1984-2004 forecasted with the $0.5^{\circ} \times 0.5^{\circ}$ version of the GFS model and analysis used to verify the HRF forecast advisory for central Vietnam, as proposed by Chen et al. (2012). Including these five cases, we have GFS forecasts for $35 \mathrm{CSV}\left(\mathrm{HRF}^{3}\right)$ s available for the present study. Although intensities for the GFS CSV $\left(\mathrm{HRF}^{3}\right) \mathrm{s}$ and CSVs are generally underforecasted, as depicted in Fig. $2 \mathrm{~b}$, the threshold value for $\zeta(925 \mathrm{hPa}) \geq 1.8 \times 10^{-5} \mathrm{~s}^{-1}$ is still used to measure the forecasted intensity of vortices for these two groups. Intensity time series for these two groups of vortices are shown in Fig. 2b. From the beginning of day 1 , the GFS CSV intensity exhibits a decreasing trend. From day 2 forward, no significant decreasing trend is seen until the end of day 4 . Then, a significant decreasing trend appears for the next three days. By the end of day 7, these CSVs are no longer notable.

Different from the observations, the GFS CSV $\left(\mathrm{HRF}^{3}\right) \mathrm{s}$ do not exhibit a notable increasing trend until the end of day 4 , but then follow a decreasing trend after the end of day 5. The second peak intensities of GFS CSV $\left(\mathrm{HRF}^{3}\right) \mathrm{s}$ appear on days 3-5 as the observations, but forecast peak intensities are weaker than the observations by more than $0.2 \times 10^{-5} \mathrm{~s}^{-1}$. The GFS CSV $\left(\mathrm{HRF}^{3}\right) \mathrm{s}$ with their third peak intensity start to form on day $5 ; 11$ are forecasted and form by day 5,1 day ahead of observed $\mathrm{HRF}^{3}$ events. Thus, two sufficient requirements for the formation of $\mathrm{HRF}^{3}$ events cannot be satisfied by the GFS CSV $\left(\mathrm{HRF}^{3}\right)$ $\mathrm{s}$ with their third peak intensity (see supplement 4 in the online supplemental material).

The second peak intensity for $\operatorname{CSV}\left(\mathrm{HRF}^{3}\right)$ is a crucial intensification process for $\mathrm{CSV}\left(\mathrm{HRF}^{3}\right) \mathrm{s}$ that develop into $\mathrm{HRF}^{3}$ events. This peak intensity is also a practical means of distinguishing between $\operatorname{CSV}\left(\mathrm{HRF}^{3}\right) \mathrm{s}$ and CSVs. Any procedure for improving the forecast for the occurrence of the $\operatorname{CSV}\left(\mathrm{HRF}^{3}\right)$ second peak intensity, in turn, will improve the forecast for the formation of $\mathrm{HRF}^{3}$ events. The occurrence times for the $\operatorname{CSV}\left(\mathrm{HRF}^{3}\right)$ second peak intensity are displayed in Fig. 4a from day 0. With the optimum time $\leq 3$ days $6 \mathrm{~h}$, the occurrence times for the GFS CSV $\left(\mathrm{HRF}^{3}\right)$ second peak intensity (Fig. 4b) coincide with those for the observed CSV $\left(\mathrm{HRF}^{3}\right) \mathrm{s}$ (Fig. 4a). If this optimum time $\left(t_{o}=3\right.$ days $\left.6 \mathrm{~h}\right)$ 


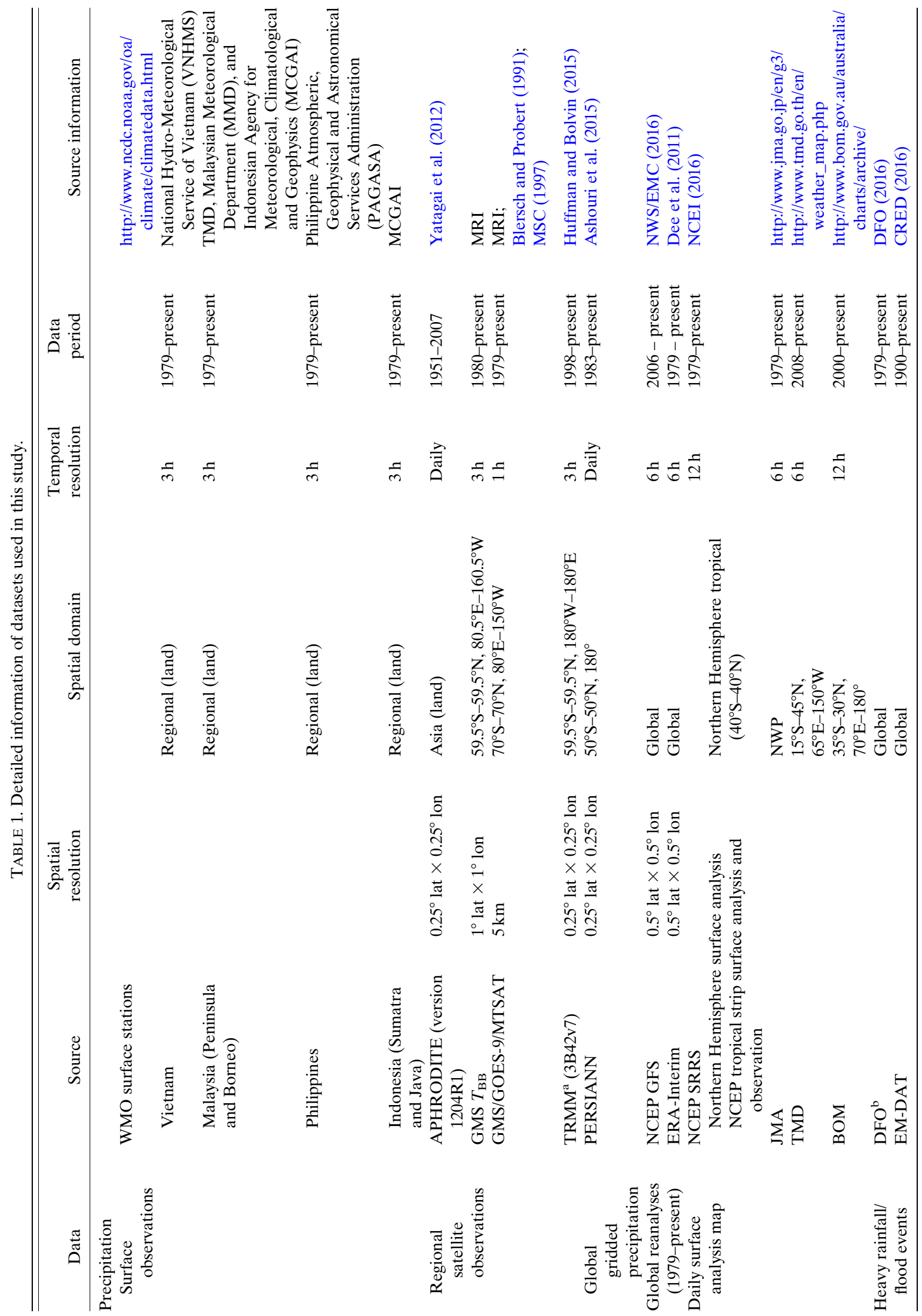


is adopted to forecast the $\operatorname{CSV}\left(\mathrm{HRF}^{3}\right)$ second peak intensity against the GFS forecasts every $6 \mathrm{~h}$, the contrast between Figs. $4 \mathrm{a}$ and $4 \mathrm{~b}$ shows the relay forecast at $t^{\circ}=$ $t_{o}+t_{r}$ is a feasible method to filter nondeveloping CSVs, where $t_{r}=$ observation time of occurrence - optimum time $t_{o}$.

The intensity and occurrence time of the second peak intensity for GFS CSV(HRF)s (Fig. 4b) are close to the observations (Fig. 4a). The performance assessment of the GFS forecasts for the second peak intensity of $\operatorname{CSV}\left(\mathrm{HRF}^{3}\right) \mathrm{s}$ is assessed by the forecast accuracy with some basic characteristics of $\mathrm{CSV}\left(\mathrm{HRF}^{3}\right) \mathrm{s}$ at their second peak intensity: errors of occurrence time, intensity, location, and hydrological condition.

\section{1) OCCURRENCE TIME}

Shown in Fig. 4a, the occurrence time of the second peak intensity for a great majority of the $\operatorname{CSV}\left(\mathrm{HRF}^{3}\right)$ is on days 4-5, after $\operatorname{CSV}\left(\mathrm{HRF}^{3}\right)$ formation. Using $t_{o}=3$ days $6 \mathrm{~h}$ as the optimum time and following the relay forecasts (Fig. 4b) for the occurrence time of the $\mathrm{CSV}\left(\mathrm{HRF}^{3}\right)$ second peak intensity, the occurrence time error is zero (Fig. 5a).

\section{2) INTENSITY}

The area-averaged $\zeta(925 \mathrm{hPa})$ of the observed $\operatorname{CSV}\left(\mathrm{HRF}^{3}\right)$ second peak intensity for 35 identified cases is $2.64 \times 10^{-5} \mathrm{~s}^{-1}$ (Fig. 5b, bottom). The error for the GFS-forecasted CSV(HRF) second peak intensity at $t^{o}=t_{o}+t_{r}$ against the area-averaged $\zeta(925 \mathrm{hPa})$ of 35 observation $\operatorname{CSV}\left(\mathrm{HRF}^{3}\right) \mathrm{s}$ is $7 \%$. Therefore, the GFS forecast bias at $t^{o}$ for the $\mathrm{CSV}\left(\mathrm{HRF}^{3}\right)$ second peak intensity is acceptable.

\section{3) $\operatorname{CSV}\left(\mathrm{HRF}^{3}\right)$ LOCATION}

Observed (solid red triangle) and forecasted (open blue triangle) locations of $\operatorname{CSV}\left(\mathrm{HRF}^{3}\right)$ second peak intensity are shown in the bottom panel of Fig. 5c. All 35 $\mathrm{CSV}\left(\mathrm{HRF}^{3}\right)$ s are classified into two groups: propagating and trapped. The former group consists of $\operatorname{CSV}\left(\mathrm{HRF}^{3}\right)$ $\mathrm{CV}, \mathrm{CSV}\left(\mathrm{HRF}^{3}\right) \mathrm{PM}, \mathrm{CSV}\left(\mathrm{HRF}^{3}\right) \mathrm{BM}, \mathrm{CSV}\left(\mathrm{HRF}^{3}\right) \mathrm{PS}$, and $\mathrm{CSV}\left(\mathrm{HRF}^{3}\right) \mathrm{BS}$, while the latter group includes only $\operatorname{CSV}\left(\mathrm{HRF}^{3}\right) \mathrm{BO}$ and $\mathrm{CSV}\left(\mathrm{HRF}^{3}\right) \mathrm{JV}^{2}$. The forecast location error of the first group is measured by the ratio between the following two distances: 1) the distance difference between the forecasted (blue open triangle) and observed (solid red triangle) locations of $\operatorname{CSV}\left(\mathrm{HRF}^{3}\right)$ second peak intensity and 2) the distance traveled by $\operatorname{CSV}\left(\mathrm{HRF}^{3}\right)$ from its formation location (red dot) to where its second peak intensity occurs. For the second group, $\mathrm{CSV}\left(\mathrm{HRF}^{3}\right) \mathrm{s}$ are trapped in Borneo.

The forecasted location errors for the second peak intensity of the first $\mathrm{CSV}\left(\mathrm{HRF}^{3}\right)$ group are projected onto a clock (Fig. 5c, top). These errors are less than 

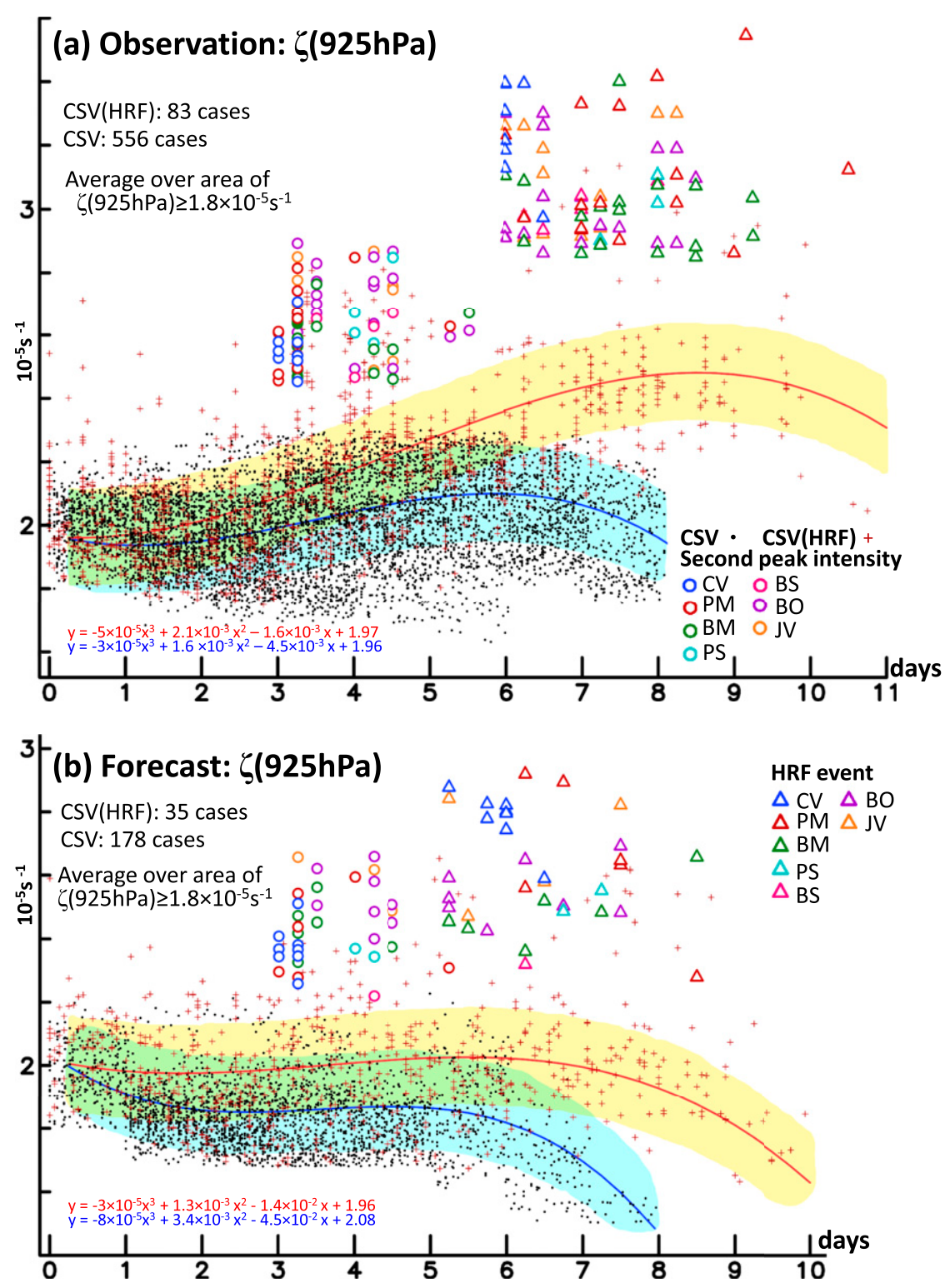

FIG. 2. (a) Temporal evolution of $556 \mathrm{CSVs}$ (black dots) and $83 \mathrm{CSV}\left(\mathrm{HRF}^{3}\right)$ (red crosses) depicted with $\zeta(925 \mathrm{hPa})$ averaged over the area of these vortices with a threshold value $\zeta(925 \mathrm{hPa}) \geq 1.8 \times 10^{-5} \mathrm{~s}^{-1}$ for 37 cold seasons over the 1979-2016 period. The second and third peak intensities for $\mathrm{CSV}\left(\mathrm{HRF}^{3}\right)$ are indicated by open circles and triangles, respectively. The red line [the third-order polynomial regression line for the area-averaged $\zeta(925 \mathrm{hPa})$ of $\operatorname{CSV}\left(\mathrm{HRF}^{3}\right)$ ] is superimposed onto a light yellow strip [one standard deviation for the areaaveraged $\zeta(925 \mathrm{hPa})$ of $\left.\mathrm{CSV}\left(\mathrm{HRF}^{3}\right)\right]$. The blue third-order polynomial regression line superimposed on the light-blue strip is the same for CSVs. (b) As in (a), but for 178 GFS CSVs and 35 GFS CSV $\left(\mathrm{HRF}^{3}\right)$ s for 12 cold seasons during the 2004-16 period.

$10 \%$ and west of the observed locations. Forecast location errors for the second $\mathrm{CSV}\left(\mathrm{HRF}^{3}\right)$ group are $\sim 25 \mathrm{~km}$ (Fig. 5c, middle).

\section{4) HydrologicAl CONDitions}

The most important variable for the $\operatorname{CSV}\left(\mathrm{HRF}^{3}\right)$ development into an $\mathrm{HRF}^{3}$ event is rainfall $P$. Its maintenance can be illustrated with the approximated water vapor budget: $P \sim-\nabla \cdot \mathbf{Q}$. The observed area-averaged $(P,-\nabla \cdot \mathbf{Q})$ of all $35 \mathrm{CSV}(\mathrm{HRF}) \mathrm{s}$ over their areas with $P \geq 45 \mathrm{~mm} \mathrm{day}^{-1}$ at their second peak intensity are shown in the bottom panel of Fig. 5d. Compared with $(P,-\nabla \cdot \mathbf{Q})$ of the observed $\operatorname{CSV}\left(\mathrm{HRF}^{3}\right) \mathrm{s}$, the averaged forecast errors for $(P,-\nabla \cdot \mathbf{Q})$ are slightly $\gtrsim 25 \%$. Clearly, forecasted 


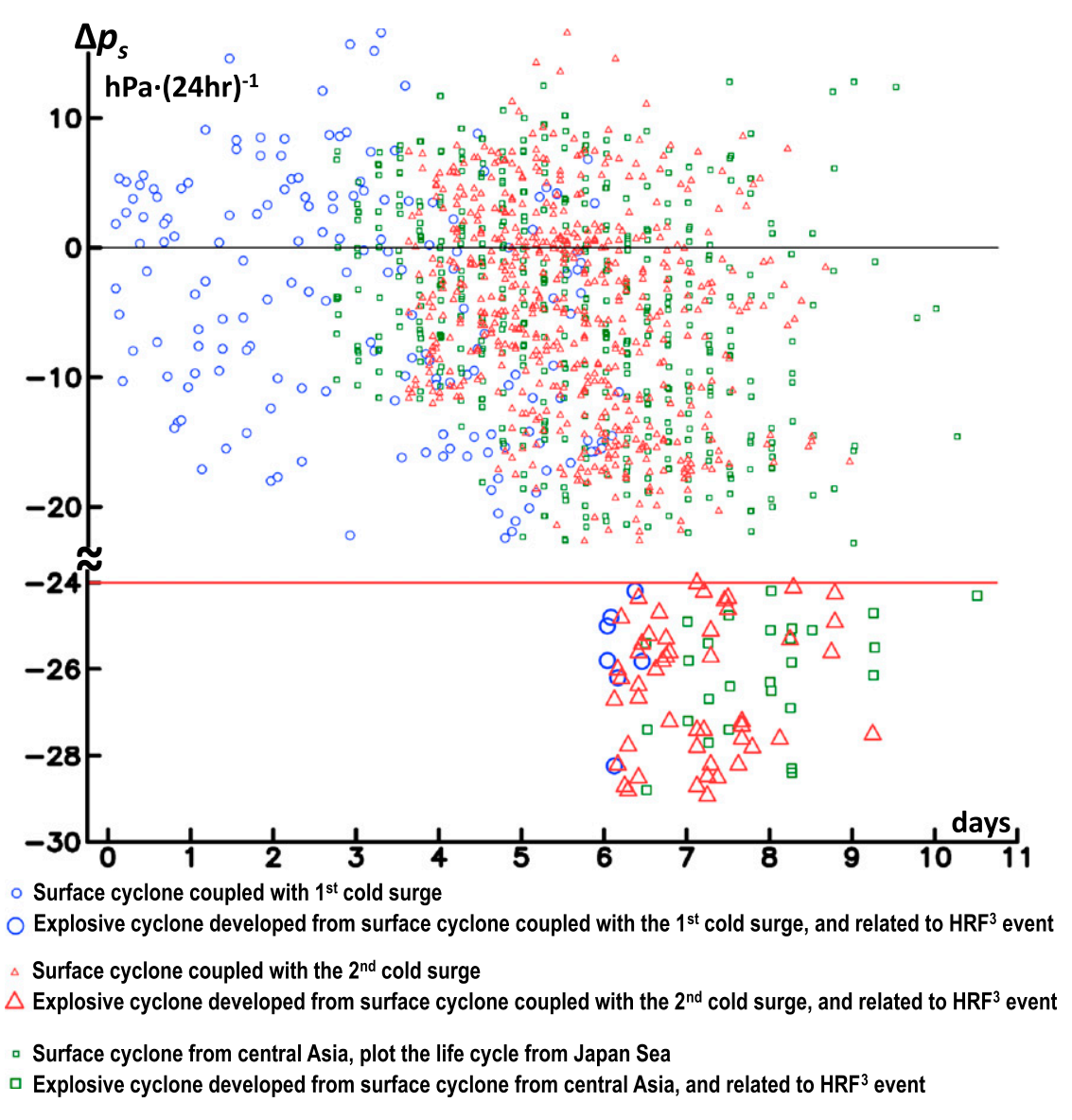

FIG. 3. Life cycle of the surface low coupled with the cold-surge flow involved with different stages of the $\operatorname{CSV}\left(\mathrm{HRF}^{3}\right)$ development into NWP explosive cyclones: 1) $\mathrm{CSV}\left(\mathrm{HRF}^{3}\right)$ formation (small blue circles), 2) second peak intensity of $\mathrm{CSV}\left(\mathrm{HRF}^{3}\right)$ (small red triangles), and 3) formation of an NWP explosive cyclone from the central Asian surface low (small green squares) without any linkage to $\mathrm{CSV}\left(\mathrm{HRF}^{3}\right)$ until the formation of the $\mathrm{HRF}^{3}$ event. NWP explosive cyclones developed from the three different types of surface lows are marked by larger blue circles, red triangles, and green squares, respectively.

CSV(HRF)s are drier than observed CSV $\left(\mathrm{HRF}^{3}\right)$ s. Despite the $(P,-\nabla \cdot \mathbf{Q})$ reductions of GFS CSV $\left(\operatorname{HRF}^{3}\right)$ s at their second peak intensity being less than observed, their signals in the forecasted development of CSV(HRF)s are not obscured by this hydrological weakening.

\section{b. Relay forecast for occurrences of HRF events}

After reaching second peak intensity, the time needed for the $\operatorname{CSV}(\mathrm{HRF}) \mathrm{s}$ to develop into a corresponding $\mathrm{HRF}^{3}$ event is shown in Fig. 6a. The preferred times needed by the second peak intensified $\operatorname{CSV}\left(\mathrm{HRF}^{3}\right)$ to form $\mathrm{HRF}^{3}$ events are 3 days $(51 \%), 4$ days $(40 \%)$, and 5 days $(9 \%)$. The optimum times for the formation of an $\mathrm{HRF}^{3}$ event from its parent $\mathrm{CSV}\left(\mathrm{HRF}^{3}\right)$ 's second peak intensity is also the time needed for the NP basin-scale circulation to develop an environment to facilitate the formation of an HRF event over the rainfall center around the SCS.
As can be seen from a comparison of occurrence times and intensities between the observation $\mathrm{HRF}^{3}$ events and the third peak intensity of the GFS CSV $\left(\mathrm{HRF}^{3}\right)$ in Fig. 2, significant disparities emerge: 1$)$ the $\operatorname{GFS~CSV}\left(\mathrm{HRF}^{3}\right)$ 's third peak intensity forms/occurs earlier and 2) intensities are weaker than the observations. To properly use the GFS forecasts for the formation/occurrence of $\mathrm{HRF}^{3}$ events, the relay forecast procedure in Fig. 4 is adopted. Shown in Fig. 6a, the optimum time needed for the formation/occurrence of an of $\mathrm{HRF}^{3}$ event from its parent's $\operatorname{CSV}\left(\mathrm{HRF}^{3}\right)$ second peak intensity remains 3 days $6 \mathrm{~h}$. Based on this optimum time, the relay GFS forecasts used to predict the formation/occurrence of $\mathrm{HRF}^{3}$ events are shown in Fig. 6b. Following the measurements for the forecast errors of the $\mathrm{CSV}\left(\mathrm{HRF}^{3}\right)$ 's second peak intensity, the forecast errors for 1) occurrence time, 2) intensity, 3) formation location, and 4) hydrological conditions for an $\mathrm{HRF}^{3}$ event/cyclone are presented. 


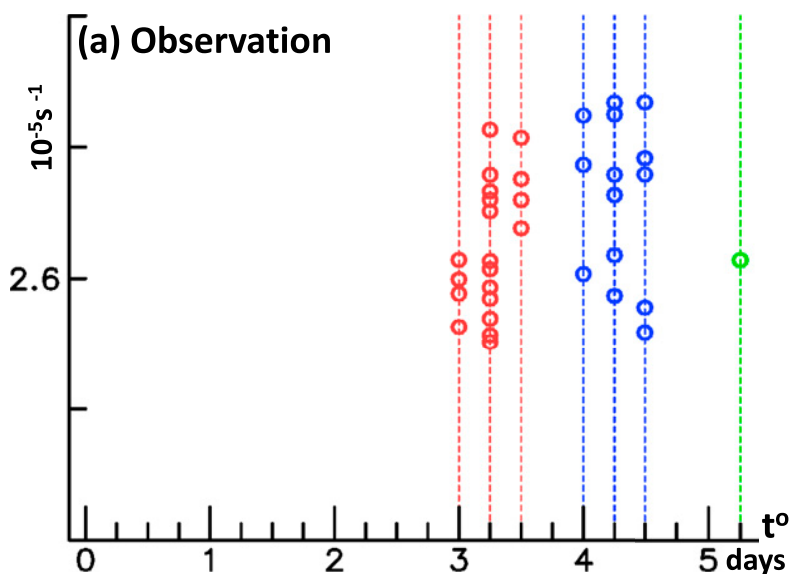

(b) Relay forecast

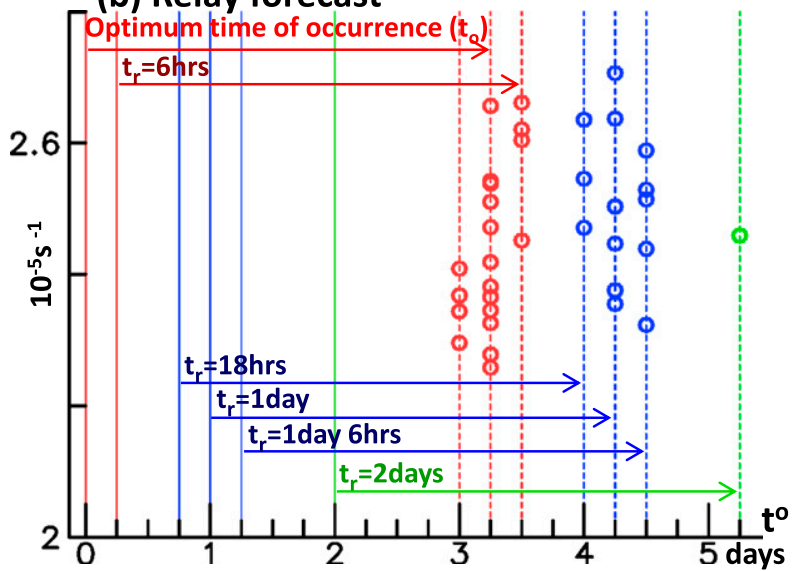

FIG. 4. (a) Occurrence time of the $\operatorname{CSV}\left(\mathrm{HRF}^{3}\right)$ second peak intensity from the $\mathrm{CSV}\left(\mathrm{HRF}^{3}\right)$ formation time (abscissa) vs the $\operatorname{CSV}\left(\mathrm{HRF}^{3}\right)$ intensity measured with the $\zeta(925 \mathrm{hPa})$ averaged over the area of $\operatorname{CSV}\left(\mathrm{HRF}^{3}\right)$ with $\zeta(925 \mathrm{hPa}) \geq 1.8 \times 10^{-5} \mathrm{~s}^{-1}$ (ordinate). The occurrence times $t^{o}$ for the $\operatorname{CSV}\left(\mathrm{HRF}^{3}\right)$ second peak are denoted by red, blue, and green open circles for the occurrence time of the $\operatorname{CSV}\left(\mathrm{HRF}^{3}\right)$ second peak intensity on days 4,5 , and 6 , respectively. (b) Illustration of the relay forecast for the second peak intensity of $\operatorname{CSV}\left(\mathrm{HRF}^{3}\right)$, based on the optimum time $\left(t_{o}=3\right.$ days $6 \mathrm{~h}$ ) for the occurrence time of the $\operatorname{CSV}\left(\mathrm{HRF}^{3}\right)$ second peak intensity. If this occurrence time $t^{o}$ is beyond the optimum time of occurrence, the relay forecast is performed from the time $t_{r}=$ observation time of occurrence $t^{o}-$ optimum time $t_{o}$, as indicated by thin, long arrows.

\section{1) OCCURRENCE TIME}

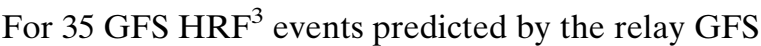
forecast approach (Fig. 6b) with the optimum time of 3 days $6 \mathrm{~h}$ ahead of their occurrences, the errors in occurrence times are zero (Fig. 7a).

\section{2) INTENSITY}

The third peak intensity is required by the occurrence of $\mathrm{HRF}^{3}$ events. To meet this requirement, $35 \mathrm{GFS} \mathrm{HRF}^{3}$ cyclones/events were identified (Fig. 2b). Their intensities are within the range of $2.3-3.0 \times 10^{-5} \mathrm{~s}^{-1}$, smaller than the corresponding observed $\mathrm{HRF}^{3}$ cyclones/events. With the relay GFS forecast approach with the optimum time (3 days 6 h) (Fig. 6b), 35 GFS HRF ${ }^{3}$ cyclones/events have an average value of $2.93 \times 10^{-5} \mathrm{~s}^{-1}$, which is only $6 \%$ (Fig. 7b) smaller than observed.

\section{3) LOCATION}

The observed center location for $35 \mathrm{HRF}^{3}$ cyclones (red crosses) and their parent $\operatorname{CSV}\left(\mathrm{HRF}^{3}\right)$ second peak intensities (red open triangle), as well as GFS forecast center locations for these $\mathrm{HRF}^{3}$ cyclones (blue crosses), are shown in the bottom panel of Fig. 7c. The forecast location errors for $\mathrm{HRF}^{3}$ cyclone centers are shown in the top panel with a clock representing the distance ratio and direction against the observed $\mathrm{HRF}^{3}$ cyclone centers. As in Fig. 5c, the outcome of error measurement is illustrated by two different approaches:

- Group I $\left[\operatorname{HRF}^{3}(\mathrm{CV}), \operatorname{HRF}^{3}(\mathrm{PM}), \operatorname{HRF}^{3}(\mathrm{BM})\right.$, $\operatorname{HRF}^{3}(\mathrm{PS})$, and $\left.\operatorname{HRF}^{3}(\mathrm{BS})\right]$, where location errors are depicted by the ratio of the distance difference between the observed and forecasted trajectory distances from the locations of the parent $\mathrm{CSV}\left(\mathrm{HRF}^{3}\right)$ 's second peak intensity to those of the $\mathrm{HRF}^{3}$ cyclones/ events, and the former trajectory distance.

- Group II $\left[\operatorname{HRF}^{3}(\mathrm{BO})\right.$ and $\left.\operatorname{HRF}^{3}(\mathrm{JV})\right]$, where these $\mathrm{HRF}^{3}$ cyclones and their parent $\mathrm{CSV}\left(\mathrm{HRF}^{3}\right) \mathrm{s}$ are trapped in Borneo. The latter may not travel over too great of a distance to reach the former. Their location errors are essentially measured with the distance shown in the middle panel of Fig. 7c.

For group I, the distance errors of their trajectories are $\leq 10 \%$, and the forecast $\mathrm{HRF}^{3}$ cyclone centers are primarily distributed north and east of the observed cyclone centers. For group II, the averaged distance error is $75 \mathrm{~km}$.

\section{4) Hydrological conditions}

Rainfall is a major concern during an $\mathrm{HRF}^{3}$ event. The area-averaged $(-\nabla \cdot \mathbf{Q})_{\mathrm{HRF}^{3}}$ is $\sim 88 \%$ of the areaaverage $P_{\mathrm{HRF}^{3}}$ over the $\mathrm{HRF}^{3}$ cyclone, about the same ratio between area-averaged $P$ and $-\nabla \cdot \mathbf{Q}$ when $\operatorname{CSV}\left(\mathrm{HRF}^{3}\right)$ s reach their second peak intensity (section 3a). This $12 \%$ difference between $P_{\mathrm{HRF}^{3}}$ and $(-\nabla \cdot \mathbf{Q})_{\mathrm{HRF}^{3}}$ (Fig. 8d, bottom) may consist of convergence of uncondensed water vapor flux, evaporation, and some computational error. Note that the GFS forecast errors of $\left[P_{\mathrm{HRF}^{3}},(-\nabla \cdot \mathbf{Q})_{\mathrm{HRF}^{3}}\right]$ are $\gtrsim 25 \%$ of the observed $\left[P_{\mathrm{HRF}^{3}},(-\nabla \cdot \mathbf{Q})_{\mathrm{HRF}^{3}}\right]$. The error may be attributed to the same factors causing the GFS forecast error of $(P,-\nabla \cdot \mathbf{Q})$ at the second peak intensity of $\operatorname{CSV}\left(\mathrm{HRF}^{3}\right)$. 

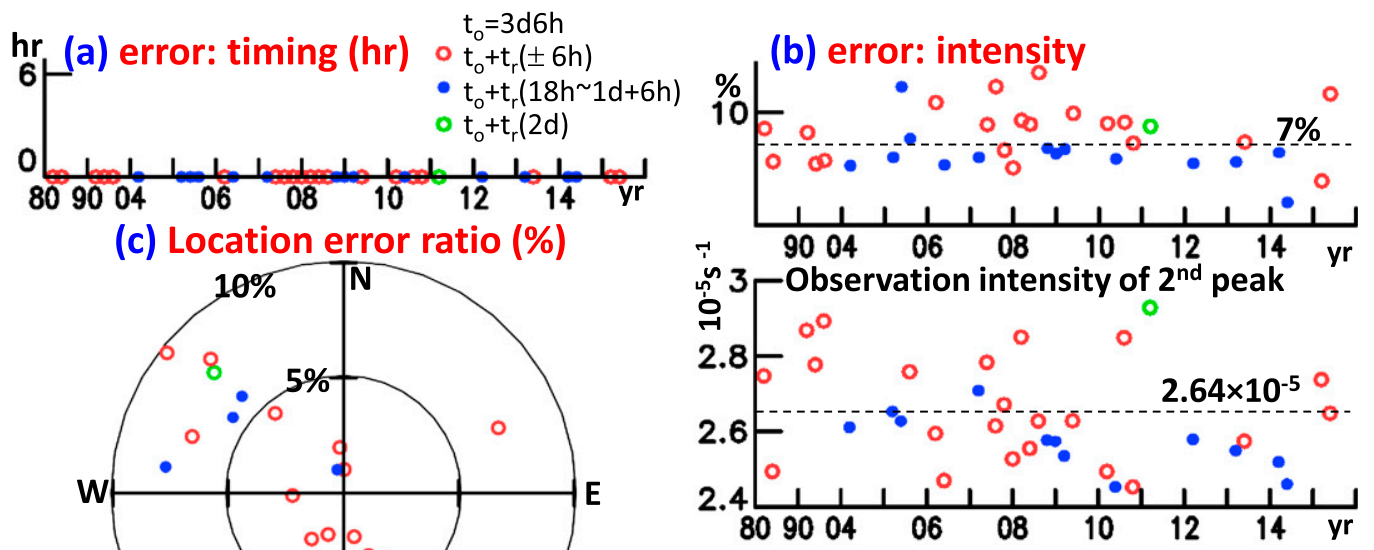

(c) Location error ratio (\%)
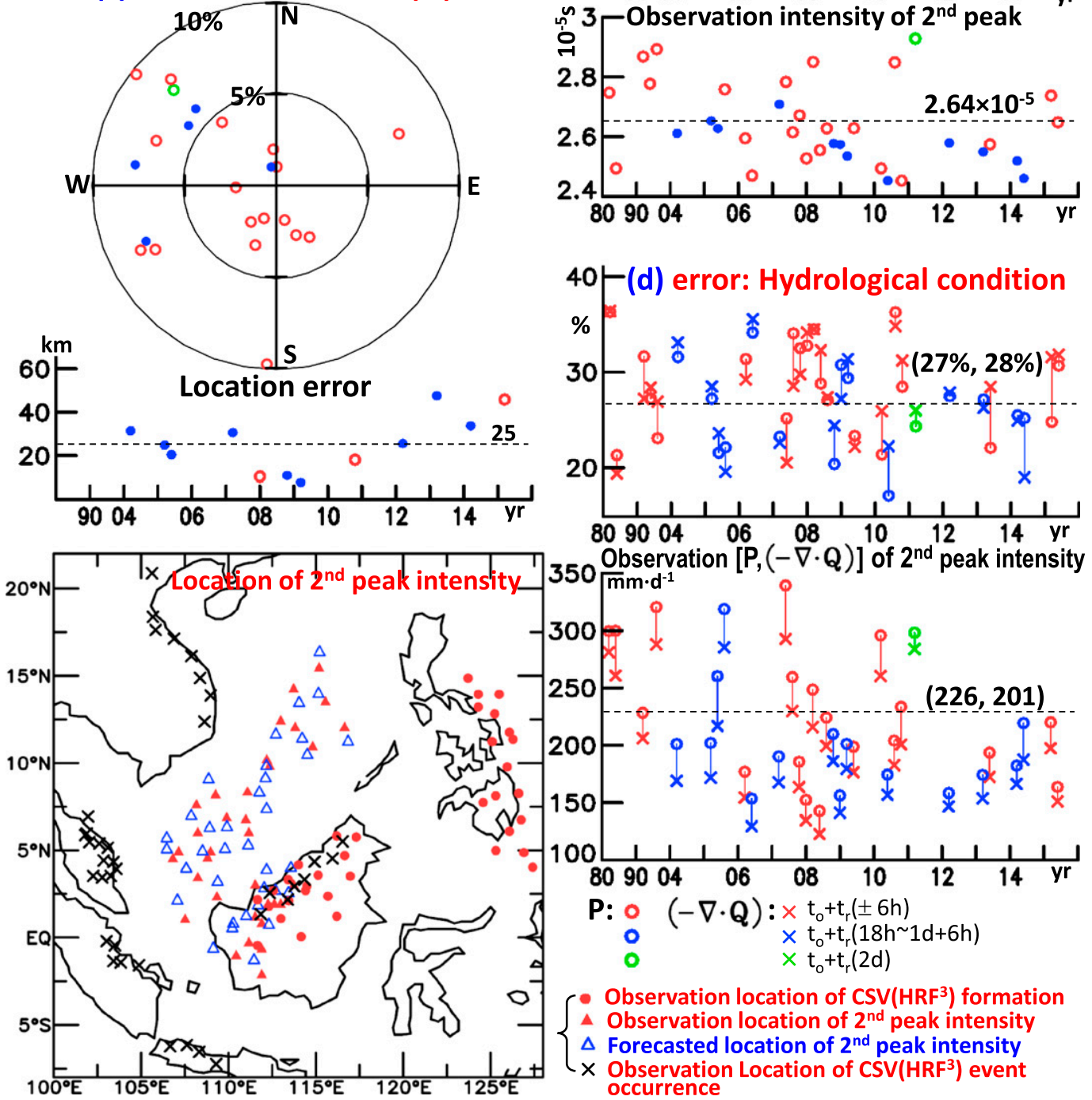

350 Observation $[P,(-\nabla \cdot Q)]$ of $2^{\text {nd }}$ peak intensity $350 \frac{\mathrm{mm}_{\mathrm{m}} \mathrm{d}^{-1}}{\mathrm{~m}}$

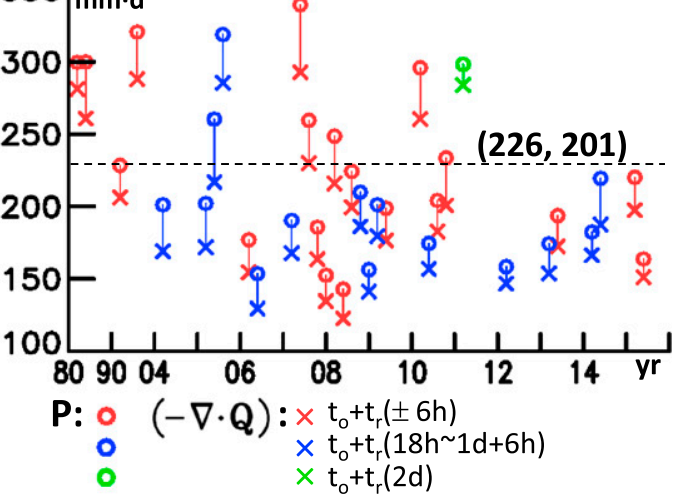

$\left\{\begin{array}{l}- \text { Observation location of } \mathrm{CSV}^{-}\left(\mathrm{HRF}^{3}\right) \text { formation } \\ \Delta \text { Observation location of } 2^{\text {nd }} \text { peak intensity } \\ \Delta \text { Forecasted location of } 2^{\text {nd }} \text { peak intensity } \\ \times \text { Observation Location of } \operatorname{CSV}\left(\mathrm{HRF}^{3}\right) \text { event } \\ \text { occurrence }\end{array}\right.$

FIG. 5. Bias of relay forecasts for the $\mathrm{CSV}\left(\mathrm{HRF}^{3}\right)$ peak intensity against the observations. Shown are errors for (a) occurrence time, (b) intensity $[\zeta(925 \mathrm{hPa})]$, (c) location, and (d) hydrological condition $(P,-\nabla \cdot \mathbf{Q})$. The $\operatorname{CSV}\left(\mathrm{HRF}^{3}\right)$ s may be divided into two groups: propagating and trapped. The former group includes $\operatorname{CSV}\left(\mathrm{HRF}^{3}\right)$ $\mathrm{CV}, \operatorname{CSV}\left(\mathrm{HRF}^{3}\right) \mathrm{PM}, \operatorname{CSV}\left(\mathrm{HRF}^{3}\right) \mathrm{BM}, \mathrm{CSV}\left(\mathrm{HRF}^{3}\right) \mathrm{PS}$, and $\mathrm{CSV}\left(\mathrm{HRF}^{3}\right) \mathrm{BS}$, while the latter group consists of $\mathrm{CSV}\left(\mathrm{HRF}^{3}\right) \mathrm{BO}$ and $\mathrm{CSV}\left(\mathrm{HRF}^{3}\right) \mathrm{JV}$. The location errors for the first group are measured with the ratio of the distance difference between the forecasted and observed trajectories for $\operatorname{CSV}\left(\mathrm{HRF}^{3}\right) \mathrm{s}$, the distance of the latter trajectories, and the direction of the forecasted $\mathrm{CSV}\left(\mathrm{HRF}^{3}\right)$ location compared to the observed. The second group of $\mathrm{CSV}\left(\mathrm{HRF}^{3}\right) \mathrm{s}$ is trapped within Borneo and the location error is only measured with the distance differences between the forecasted and observed trajectories of $\mathrm{CSV}\left(\mathrm{HRF}^{3}\right)$ s. Errors for the GFS(HRF $\left.{ }^{3}\right)$ hydrological condition are measured with a ratio of the difference for $(P,-\nabla \cdot \mathbf{Q})$ averaged over the area of $\operatorname{CSV}\left(\mathrm{HRF}^{3}\right)$ with $(P,-\nabla \cdot \mathbf{Q}) \geq 45 \mathrm{~mm}$ day $^{-1}$ between the forecast and the observations. 
(a) Observation from the $2^{\text {nd }}$ peak intensity of parent $\operatorname{CSV}\left(\mathrm{HRF}^{3}\right)$

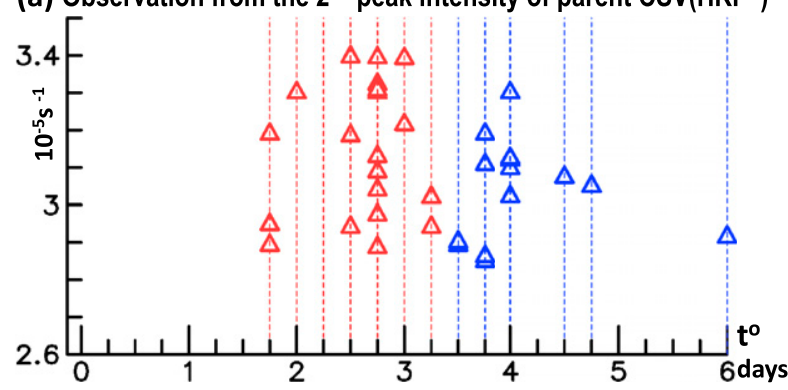

(b) Relay forecast from the $2^{\text {nd }}$ peak intensity of parent $\mathrm{CSV}\left(\mathrm{HRF}^{3}\right)$

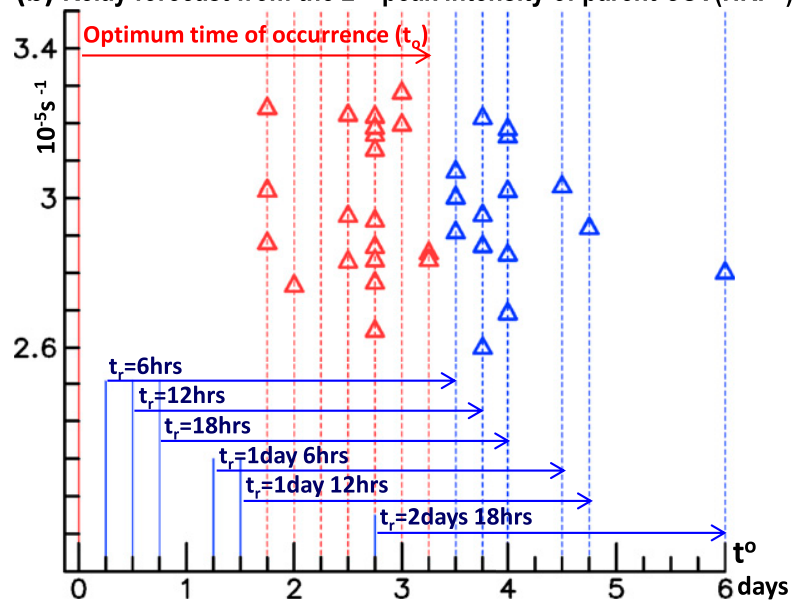

FIG. 6. As in Fig. 4, but for the relay forecasts of the third peak intensity of $\mathrm{CSV}\left(\mathrm{HRF}^{3}\right)$ formation/occurrence of $\mathrm{HRF}^{3}$ cyclone/ event. The occurrence times of a $\mathrm{HRF}^{3}$ event within and beyond the optimum time of 3 days $6 \mathrm{~h}$ are colored red and blue, respectively.

The occurrence of an $\mathrm{HRF}^{3}$ event also needs to meet the following two criteria:

1) Occurrence synchronization of the NWP explosive cyclone and HRF event/cyclone

On the occurrence dates of 35 identified $\mathrm{HRF}^{3}$ events, 35 NWP explosive cyclones are also identified. The observed surface pressure tendency $\Delta p_{S}^{o}$ for these 35 explosive cyclones is shown in Fig. 8a; Sanders and Gyakum's (1980) criterion $\Delta p_{S}^{o} \leq-24 \mathrm{hPa} \mathrm{day}^{-1}$ is marked by a dashed line. All 35 identified explosive cyclones meet this criterion. The scatter diagram of occurrence dates for the $\mathrm{HRF}^{3}$ events around the SCS (ordinate) versus occurrence dates of NWP explosive cyclones (abscissa) shows results that are distributed along the diagonal between these two axes. Apparently, occurrences of these $\mathrm{HRF}^{3}$ events and the NWP explosive cyclone synchronize.

Using the optimum time $\left(t_{o}=3\right.$ days $\left.6 \mathrm{~h}\right)$ to perform the relay forecasts for the formation of $\mathrm{HRF}^{3}$ events after the second peak intensity of their corresponding parent $\operatorname{CSV}\left(\mathrm{HRF}^{3}\right) \mathrm{s}$, the $\Delta p_{S}^{F}$ values of the GFS explosive cyclones that correspond to the GFS HRF ${ }^{3}$ events are shown in Fig. 8c. Chen et al.'s (2012) criterion for the $\Delta p_{S}^{F}$ forecasted value of the GFS explosive cyclone is $\leq-15 \mathrm{hPa} \mathrm{day}^{-1}$ and is marked by a dashed line. The scatter diagram for the occurrence date of GFS $\mathrm{HRF}^{3}$ events versus the occurrence date of GFS NWP explosive cyclones shows results that are distributed along the diagonal as observed (Fig. 8b). The occurrence of the GFS NWP explosive cyclone and the GFS $\mathrm{HRF}^{3}$ events synchronize.

2) Simultaneous occurrences of maximum intensities in three weather systems: HRF cyclone/event, NP subtropical anticyclone, and NWP explosive cyclone

Following Chen et al.'s (2012) approach, shown in Figs. 9a-c are time series (blue lines) for the maximum westerlies at the formation longitude of an HRF event $u_{\mathrm{HRF}}^{o}(850 \mathrm{hPa})$, and the maximum 850-hPa tropical trade easterlies of the NP subtropical anticyclone $u_{\mathrm{TTE}}^{o}(850 \mathrm{hPa})$ and the maximum 850-hPa westerlies at the formation longitude of an NWP explosive cyclone $u_{\mathrm{PEC}}^{o}(850 \mathrm{hPa})$. The composite time series for $u_{\mathrm{HRF}}^{o}(850 \mathrm{hPa}), u_{\mathrm{TTE}}^{o}(850 \mathrm{hPa})$, and $u_{\mathrm{PEC}}^{o}(850 \mathrm{hPa})$ are denoted by thick red lines superimposed on the corresponding time series in Figs. 9a-c, respectively. It is clear that the $\mathrm{HRF}^{3}$ event is formed when simultaneous occurrences of maximum intensities of $u_{\mathrm{PEC}}^{o}(850 \mathrm{hPa}), u_{\mathrm{TTE}}^{o}(850 \mathrm{hPa})$, and $u_{\mathrm{HRF}}^{o}(850 \mathrm{hPa})$ occur on day 0 .

The requirement for the simultaneous occurrence of maximum intensities in three weather systems with the GFS forecasts is shown in Figs. 9d-f. The GFS forecasts for $35 \mathrm{HRF}^{3}$ events in Fig. 9 are used to prepared the time series for $u_{\mathrm{PEC}}^{F}(850 \mathrm{hPa}), u_{\mathrm{TTE}}^{F}(850 \mathrm{hPa})$, and $u_{\mathrm{HRF}}^{F}(850 \mathrm{hPa})$. However, the data used to construct the time series ahead of the forecasts are gathered from observations. Despite the bias in the GFS relay forecasts with the optimum time of 3 days $6 \mathrm{~h}$ shown in Fig. 7, the simultaneous occurrence requirement of maximum intensity in the three weather systems $\left(\mathrm{HRF}^{3}\right.$ cyclone/ event, NP subtropical anticyclones, and NWP explosive cyclone) are well met by the GFS relay forecasts.

\section{Forecast advisory}

The life cycle of an $\mathrm{HRF}^{3}$ event from the formation of its parent $\operatorname{CSV}\left(\mathrm{HRF}^{3}\right)$ to the occurrence of the $\mathrm{HRF}^{3}$ event varies from 6 to 10 days (Fig. 1). Regional weather services, such as the Malaysia Meteorological Department (Maisarah et al. 2013), the Vietnam National Hydrometeorological Service (UNISDR 2013), and the 

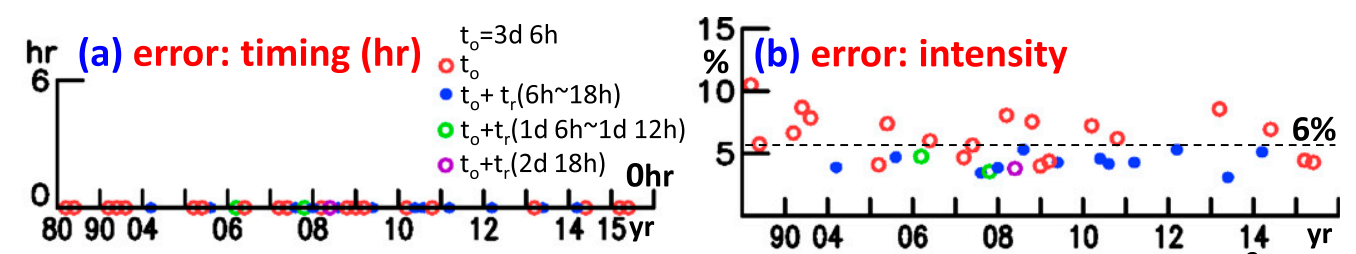

(c) Location error ratio (\%)
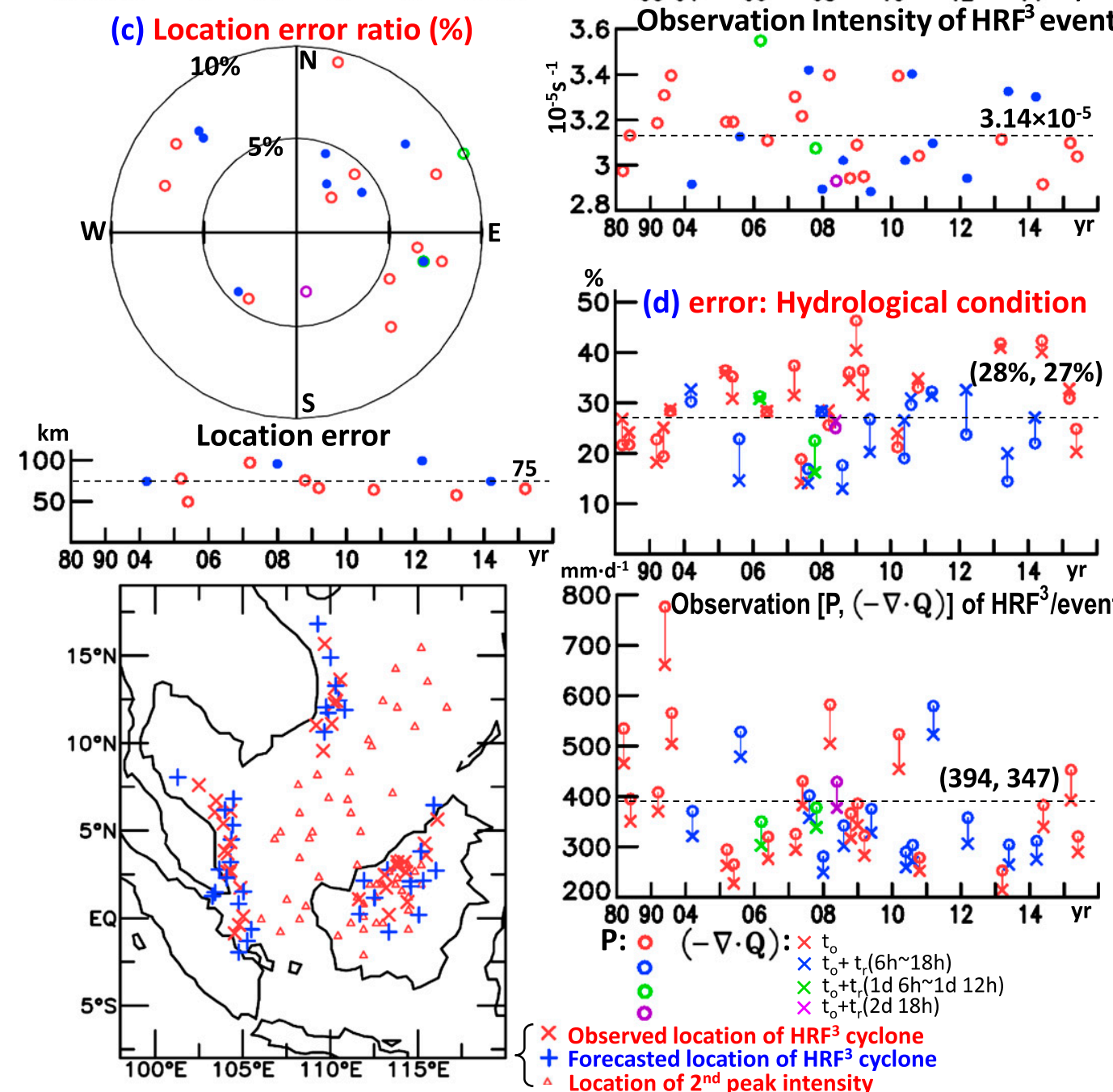

$10-$
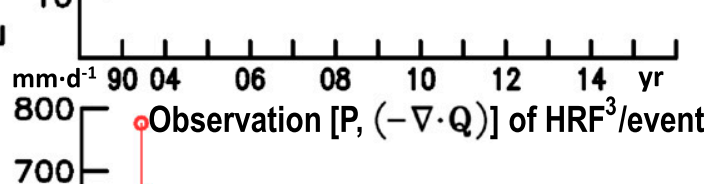

${ }^{800}$ [ Observation $[\mathrm{P},(-\nabla \cdot \mathrm{Q})]$ of $\mathrm{HRF}^{3}$ /event

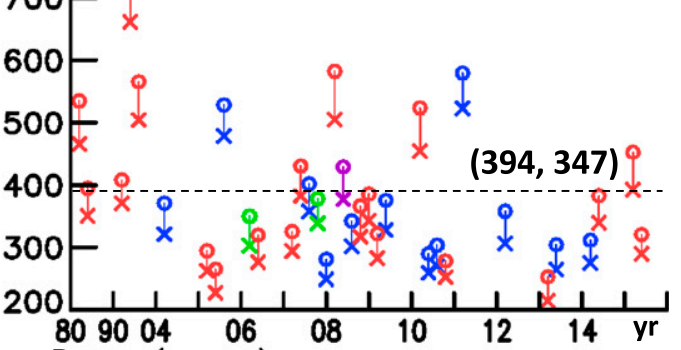

$\mathbf{P :}: \circ(-\nabla \cdot \mathbf{Q}): \times \mathrm{t}_{0} \times \mathrm{t}_{0}+\mathrm{t}_{\mathrm{t}}(6 \mathrm{~h} \sim 18 \mathrm{~h})$

- $\quad \times t_{0}+t_{r}(1 d 6 h \sim 1 d 12 h)$

0

$\times \mathrm{t}_{\mathrm{o}}+\mathrm{t}_{\mathrm{r}}(2 \mathrm{~d} 18 \mathrm{~h})$

$\left\{x\right.$ Observed location of $\mathrm{HRF}^{3}$ cyclone

+ Forecasted location of HRF $^{3}$ cyclone

FIG. 7. As in Fig. 5, but for relay forecasts of the third peak intensity of $\operatorname{CSV}\left(\mathrm{HRF}^{3}\right)$ formation of occurrence of an $\mathrm{HRF}^{3}$ cyclone/event.

Meteorological Research Institute of JMA (Saito et al. 2012) use different regional forecast models and their products to predict HRF events. These endeavors often have less than satisfactory outcomes even with short-range forecasts for HRF events. The NCEP GFS provides a 16-day global forecast outlook (NWS/EMC 2016), but accurate forecasts for $\mathrm{CSV}\left(\mathrm{HRF}^{3}\right)$ s with a long life cycle are still beyond the reach of state-of-the-art numerical weather prediction techniques. As shown by the GFS forecast compared with observations presented in section 3 , the optimum forecast time for both the second peak intensity of $\operatorname{CSV}\left(\mathrm{HRF}^{3}\right) \mathrm{s}$ from its formation and the formation/occurrence of $\mathrm{HRF}^{3}$ events from the second peak intensity of their parents $\operatorname{CSV}\left(\mathrm{HRF}^{3}\right) \mathrm{s}$ is about 3 days $6 \mathrm{~h}$. This time assessment is based on there being zero error in the occurrence time, error $\leq 10 \%$ in intensity and location, and error $>25 \%$ in $(P,-\nabla \cdot \mathbf{Q})$ of $\operatorname{CSV}\left(\mathrm{HRF}^{3}\right) \mathrm{s}$ at their second peak intensity and during the formation of $\mathrm{HRF}^{3}$ events. As summarized in the flowchart in Fig. 10, these findings allow us to introduce a forecast advisory with the relay forecast approach to predict the development of $\mathrm{CSV}\left(\mathrm{HRF}^{3}\right) \mathrm{s}$ over their entire life cycles. 

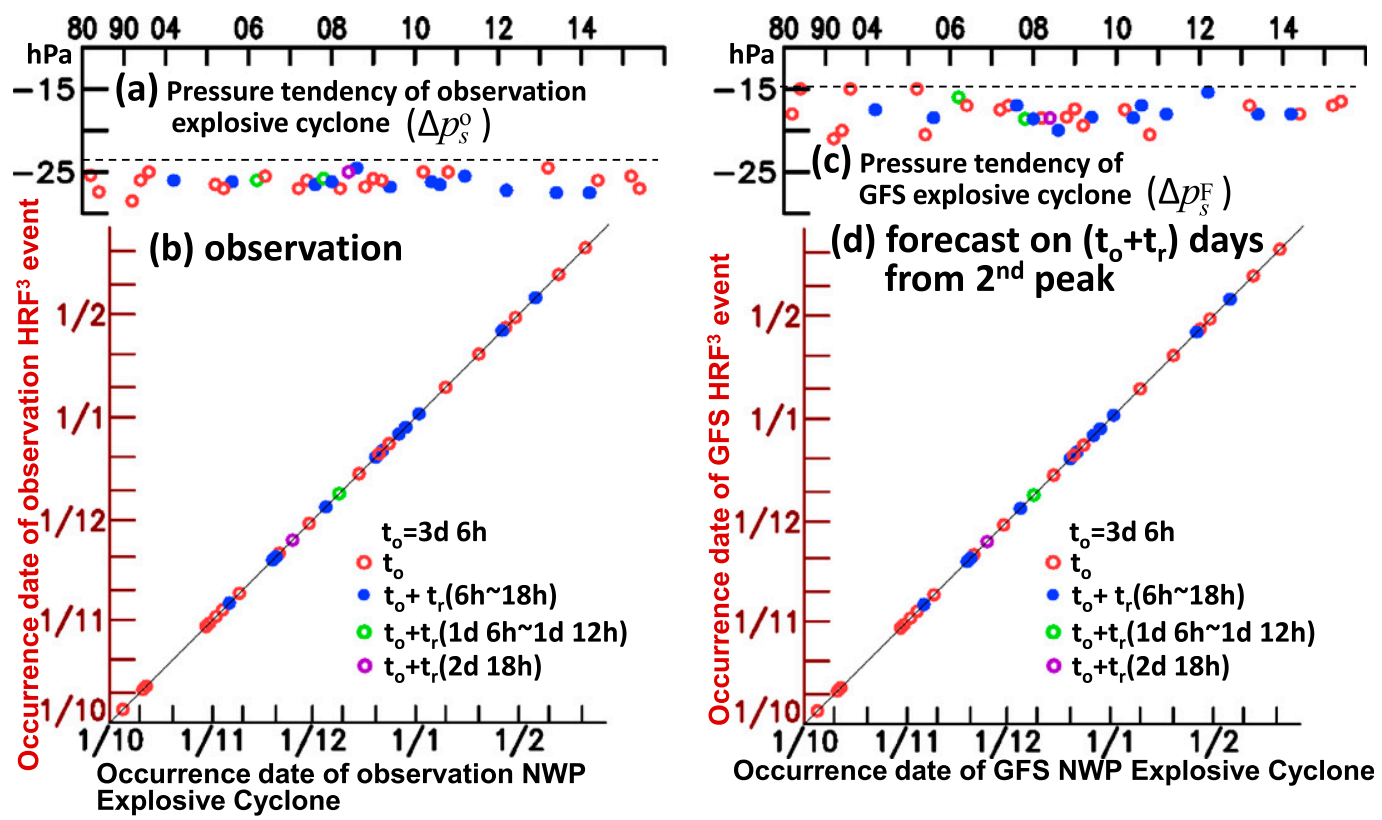

FIG. 8. (a) Surface pressure tendency $\Delta p_{S}^{o}$ of observed NWP explosive cyclones related to HRF ${ }^{3}$ events. (b) The scatter diagram for the occurrence date of an observed NWP explosive cyclone (ordinate) vs the occurrence date of an observed $\mathrm{HRF}^{3}$ event (abscissa). (c),(d) As in (a),(b), respectively, but for GFS relay forecasts of the corresponding observed NWP explosive cyclone and $\mathrm{HRF}^{3}$ event.

\section{a. Illustration of forecast advisory}

Through multiple interactions with the sequential coldsurge flows in the SCS, the development of $\operatorname{CSV}\left(\mathrm{HRF}^{3}\right) \mathrm{s}$ over their life cycles is characterized by three major processes: $\mathrm{CSV}\left(\mathrm{HRF}^{3}\right)$ formation, the second peak intensity, and the formation/occurrence of HRF events. The latter process is coupled with two special requirements: 1) occurrence synchronization of an HRF event and an NWP explosive cyclone and 2) the simultaneous occurrence of the maximum zonal winds in three weather systems over the NP basin: (i) the maximum westerlies of an $\mathrm{HRF}^{3}$ cyclone, (ii) the maximum tropical trade easterlies, and (iii) the maximum westerlies of an NWP explosive cyclone. Figure 10 illustrates a four-step forecast advisory developed from the multiple interactions of $\operatorname{CSV}\left(\mathrm{HRF}^{3}\right)$ with the SCS cold-surge flows.

\section{1) STEP 1: IDENTIFICATION OF CSV IN THE VICINITY OF THE PHILIPPINES AND BORNEO}

Prepared with GFS initial analyses as described in section 2, the 925-hPa streamline chart superimposed with TRMM rainfall/Geostationary Meteorological Satellite (GMS) or Multifunctional Transport Satellite (MTSAT; Meteorological Services Centre Japan 1997) cloud images are utilized to identify the CSV formation around the Philippines and Borneo. The daily surface analysis charts issued by weather services (JMA, TMD,
BOM, and NCEP SRRS around the SCS) are applied to verify the identified CSV. Two types of CSVs are identified: Philippines and Borneo. The former is formed around 0600 UTC over the vicinity of the Philippines, while the latter is formed around 0000 UTC in Borneo.

2) STEP 2: IDENTIFICATION OF CSV(HRF $\left.{ }^{3}\right)$ USING THE GFS FORECASTS FOR THE CSV $\left(\mathrm{HRF}^{3}\right)$ SECOND PEAK INTENSITY AND THE SURFACE LOW COUPLED WITH THE COLD-SURGE FLOW RELATED TO THE CSV $\left(\mathrm{HRF}^{3}\right)$ DEVELOPMENT

The evolution of $\operatorname{CSV}\left(\mathrm{HRF}^{3}\right)$ undergoes an intensification while reaching its second peak intensity before it develops into an $\mathrm{HRF}^{3}$ event. Although the time window for the development to gain this peak intensity is about $3-5$ days (section 3 ), the optimum time is 3 days $6 \mathrm{~h}$. This evolutionary feature of $\operatorname{CSV}\left(\mathrm{HRF}^{3}\right)$ provides a feasible way to separate it from nondeveloping CSVs. Following the procedure presented in section 3 , the area-averaged $\zeta(925 \mathrm{hPa})$ time series of the GFS forecast for an identified CSV during the first 6 days is used to examine whether the second peak intensity of this CSV appears with the area-averaged $\zeta(925 \mathrm{hPa})$ value $\geq 90 \%$ of the mean second peak intensity of observed $\mathrm{CSV}\left(\mathrm{HRF}^{3}\right)$ shown in Fig. 5b. If the time for a GFS CSV $\left(\mathrm{HRF}^{3}\right)$ to reach its second peak intensity is beyond the optimum time, the GFS forecast will be delayed to the time 3 days $6 \mathrm{~h}$ ahead of the 


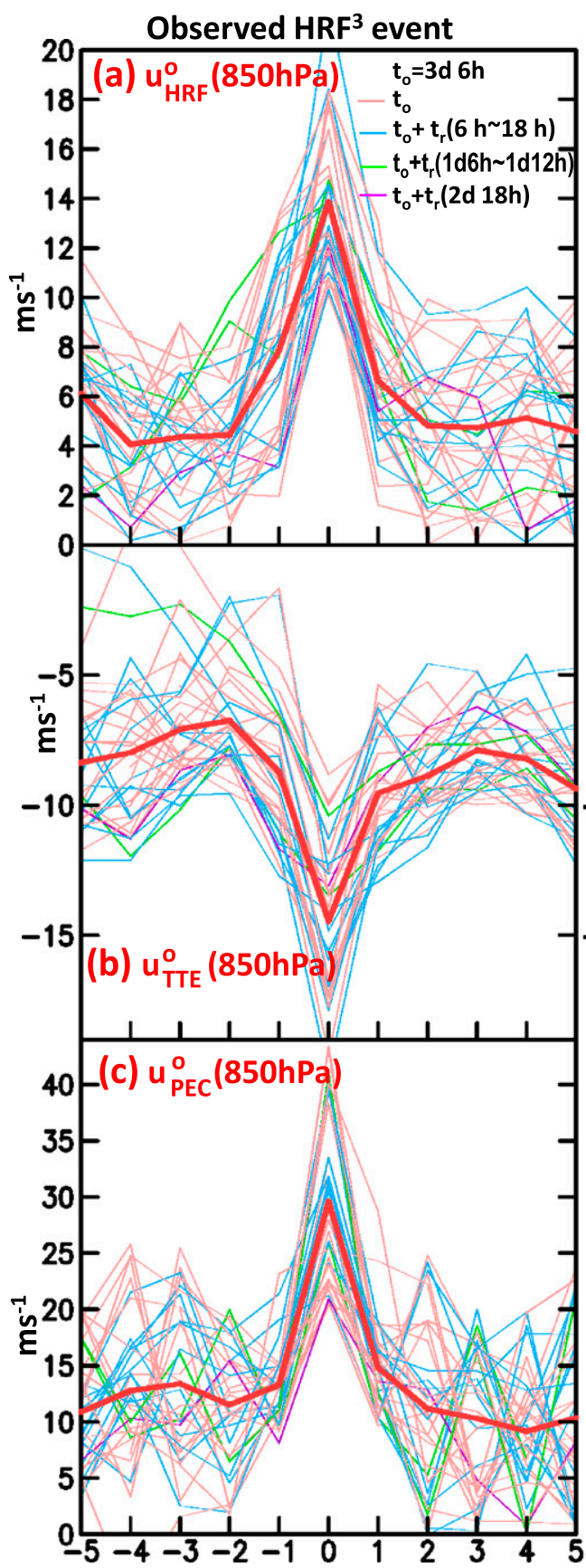

Forecast from $2^{\text {nd }}$ peak at $\left(t_{\mathrm{o}}+\mathrm{t}_{\mathrm{r}}\right)$ day
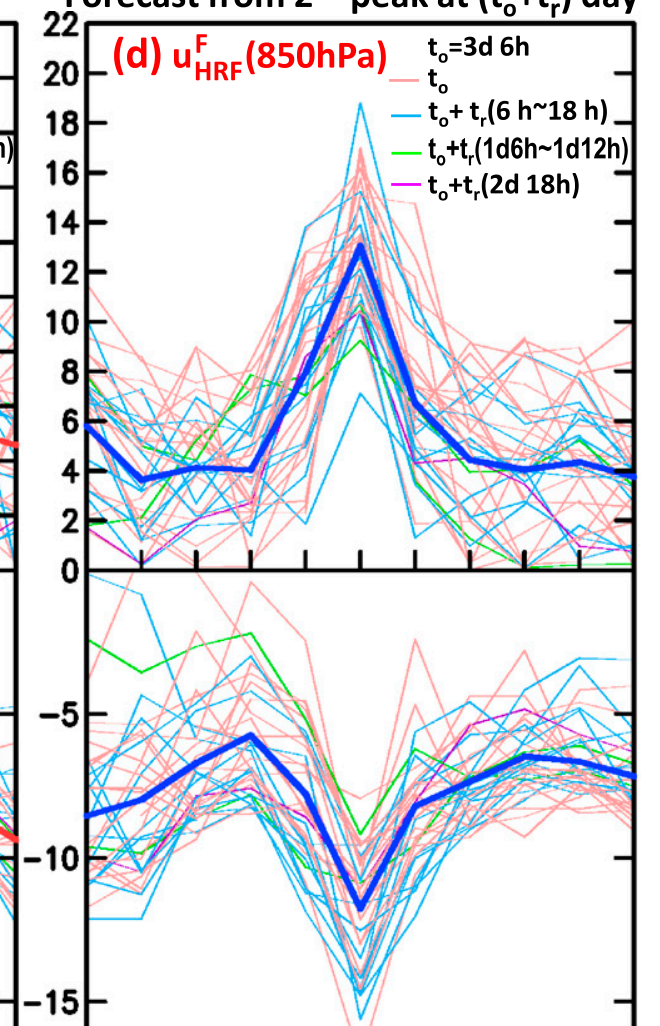

$\mathrm{U}_{\mathrm{PEC}}(850 \mathrm{hPa})$ : westerlies of the northwestern Pacific explosive cyclone

$\mathrm{U}_{\mathrm{TTE}}(850 \mathrm{hPa})$ : tropical trade easterlies of the North Pacific subtropical anticyclone

$\mathrm{u}_{\mathrm{HRF}}(85 \mathrm{hPa})$ : easterlies of $\mathrm{HRF}^{3}$ cyclone/event

FIG. 9. Time series for $u(850 \mathrm{hPa})$ at locations of the maximum 850 -hPa zonal winds of three weather systems of interest: (a) $u_{\mathrm{HRF}}^{o}(850 \mathrm{hPa})$, (b) $u_{\mathrm{TTE}}^{o}(850 \mathrm{hPa})$, and (c) $u_{\mathrm{PEC}}^{o}(850 \mathrm{hPa})$, related to the formation/occurrence of 35 $\mathrm{HRF}^{3}$ events. These observational $u(850 \mathrm{hPa})$ time series are depicted by thin lines with colors corresponding to the HRF events shown in Fig. 6a. A thick red line in (a)-(c) exhibits the mean time series for $35 \mathrm{HRF}^{3}$ events. Time series for GFS (d) $u_{\mathrm{HRF}}^{F}(850 \mathrm{hPa}),(\mathrm{e}) u_{\mathrm{TTE}}^{F}(850 \mathrm{hPa})$, and (f) $u_{\mathrm{PEC}}^{F}(850 \mathrm{hPa})$, as in (a)-(c), for relay forecasts of $\mathrm{HRF}^{3}$ events from the second peak intensities of $35 \mathrm{CSV}\left(\mathrm{HRF}^{3}\right)$ s. Results are presented by different colors corresponding to the delay time shown in Fig. 6b. The mean time series for $35 \mathrm{HRF}$ events are displayed by the thick dark-blue lines in (d)-(f). 


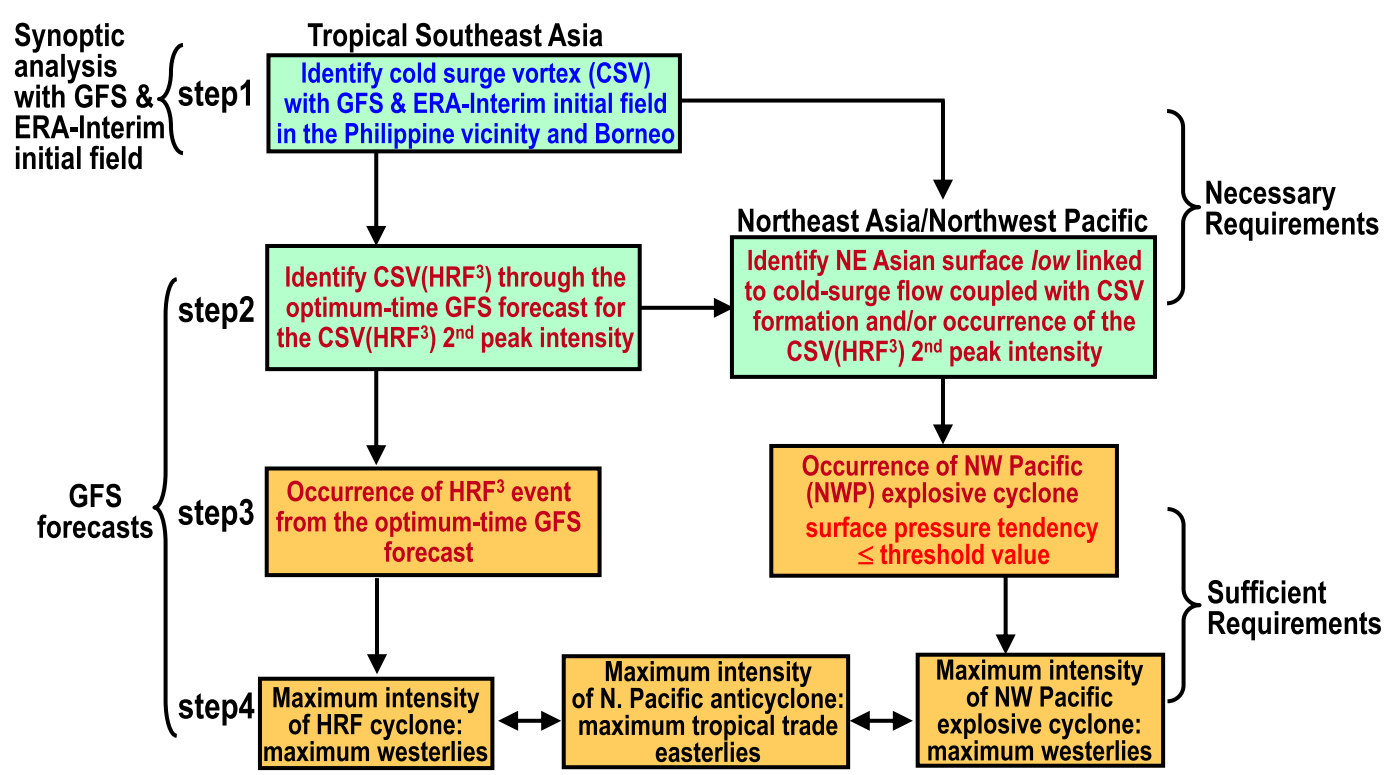

FIG. 10. Flowchart of the forecast advisory for the cold-season $\mathrm{HRF}^{3}$ events developed from multiple interactions with the cold-surge flows in the SCS that occurred over the rainfall centers around the region.

occurrence time for this $\mathrm{CSV}\left(\mathrm{HRF}^{3}\right)$ second peak intensity, as shown in Fig. 4. The forecast approach presented here serves three purposes:

(i) to separate $\mathrm{CSV}\left(\mathrm{HRF}^{3}\right)$ s from the large number of CSVs identified in step 1;

(ii) to gain a more accurate forecast time for the occurrence of the $\operatorname{CSV}\left(\mathrm{HRF}^{3}\right)$ second peak intensity, and

(iii) to track whether the surface low systems coupled with the cold-surge flow linked to either the formation or second peak intensity of $\operatorname{CSV}\left(\mathrm{HRF}^{3}\right)$ may develop into an NWP explosive cyclone synchronized with the occurrence of an $\mathrm{HRF}^{3}$ event.

\section{3) STEP 3: OCCURRENCE SYNCHRONIZATION OF THE SOUTHEAST ASIAN HRF ${ }^{3}$ EVENT AROUND THE SCS AND THE NWP EXPLOSIVE CYCLONE}

The optimum time for a great majority of $\mathrm{CSV}\left(\mathrm{HRF}^{3}\right) \mathrm{s}$ (72/83 87\%) to form $\mathrm{HRF}^{3}$ events from their second peak intensity is from about 3 days $6 \mathrm{~h}$ to 4 days $6 \mathrm{~h}$, and for some minority of the $\operatorname{CSV}\left(\mathrm{HRF}^{3}\right) \mathrm{s}(\sim 8 \%)$, the time is beyond 4 days $6 \mathrm{~h}$. Thus, the GFS forecast issued at the time a $\mathrm{CSV}\left(\mathrm{HRF}^{3}\right)$ reaches its second peak intensity for the next several days is used to determine how the relay forecast should proceed for the formation/occurrence of $\mathrm{HRF}^{3}$ events. Assume the GFS CSV $\left(\mathrm{HRF}^{3}\right)$ third peak intensity appears at the optimum time of 3 days $6 \mathrm{~h}$, three necessary procedures should be pursued:

(i) We construct the time series of area-averaged $\zeta(925 \mathrm{hPa})$ for the identified $\mathrm{CSV}\left(\mathrm{HRF}^{3}\right)$ from its formation to the formation/occurrence of the corresponding $\mathrm{HRF}^{3}$ event. If the third peak intensity of a $\mathrm{CSV}(\mathrm{HRF}) / \mathrm{HRF}$ cyclone is larger than $1.2 \sigma$ of the detrended $\zeta(925 \mathrm{hPa})$ time series, the $\mathrm{HRF}^{3}$ events should form/occur.

(ii) We confirm the occurrence/formation of the GFS NWP explosive cyclone (the deepening rate of this GFS cyclone $\leq-15 \mathrm{hPa} \mathrm{day}^{-1}$ ), as required by the occurrence synchronization of the GFS $\mathrm{HRF}^{3}$ event and the GFS NWP explosive cyclone.

(iii) If the third peak intensity of GFS CSV $\left(\mathrm{HRF}^{3}\right)$ does not appear by the optimum time of 3 days $6 \mathrm{~h}$, it may appear beyond this optimum time. In this case, the third peak intensity for $\mathrm{CSV}\left(\mathrm{HRF}^{3}\right)$ may not reach all required criteria by formation/occurrence of an $\mathrm{HRF}^{3}$ event. As illustrated in Fig. 6, the relay forecast every $6 \mathrm{~h}$ by the GFS will be checked until all required criteria are met within the optimum occurrence/formation time for a GFS $\mathrm{HRF}^{3}$ event in 3 days $6 \mathrm{~h}$. Then, the forecast for the formation/ occurrence of GFS $\mathrm{HRF}^{3}$ can be confirmed.

4) SteP 4: SimultaneOUS OCCURRENCE OF MAXIMUM INTENSITY IN THE HRF CYCLONE, THE NP ANTICYCLONE, AND THE NWP EXPLOSIVE CYCLONE

The midlatitude-tropical interaction happens not only through the northeast Asian cold-surge flow, but also the basin-scale interactions between the $\mathrm{HRF}^{3}$ cyclone and the NWP explosive cyclone through the NP subtropical anticyclone. The latter interaction is 
realized by the occurrence simultaneity among the maximum westerlies of the $\mathrm{HRF}^{3}$ cyclone/event, the maximum tropical trade easterlies of the North Pacific anticyclone, and the maximum $850-\mathrm{hPa}$ westerlies of the NWP explosive cyclone. The forecast for the formation/occurrence of GFS $\mathrm{HRF}^{3}$ is further confirmed by this requirement and can be issued in an operational setting.

\section{b. Feasibility test of the forecast advisory}

\section{1) NeCESSARY REQUiREMENTS \\ (i) CSV identification}

Based on the identification approach presented in section 2, $51 \mathrm{CSV}$ s are identified over three cold seasons (2013-15); 6 of these 51 CSVs are CSV $\left(\mathrm{HRF}^{3}\right)$ s. Additionally, one CSV developed into a central Vietnam $\mathrm{HRF}^{2}$ event and two CSVs evolved into Borneo $\mathrm{HRF}^{2}$ events through two peak intensities. However, these three CSVs were not the main concern for the current study. The temporal evaluations of 45 CSVs depicted by the GFS forecasts are marked by small black dots in Fig. 11a. They are used as reference to contrast with evaluations of six GFS CSV $\left(\mathrm{HRF}^{3}\right)$ s marked with red crosses.

(ii) $\operatorname{CSV}\left(H R F^{3}\right)$ identification and surface low tracking through the intensification of its second peak intensity

The evolution of six $\operatorname{CSV}\left(\mathrm{HRF}^{3}\right) \mathrm{s}$ is depicted with the relay forecasts of GFS shown in Figs. 11b and 11c. The second peak intensity for these six $\operatorname{CSV}\left(\mathrm{HRF}^{3}\right) \mathrm{s}$ is denoted by open circles in Figs. 11a and 11b, while the formation/occurrence for six corresponding $\mathrm{HRF}^{3}$ events is marked by open triangles in Figs. 11a and $11 \mathrm{c}$.

The population ratio between CSVs and CSV(HRF)s is $45: 6$. Therefore, it may not be feasible to track the development for every CSV. A practical, operational approach should be developed to identify the formation of $\operatorname{CSV}\left(\mathrm{HRF}^{3}\right)$ s. A third-order polynomial regression line (red) is added to indicate the $\operatorname{CSV}\left(\mathrm{HRF}^{3}\right)$ development in Fig. 11a. The second peak intensity for $\mathrm{CSV}\left(\mathrm{HRF}^{3}\right)$ s marked by open circles is notable from the GFS forecasts. The observation third peak intensities for all six $\mathrm{CSV}\left(\mathrm{HRF}^{3}\right)$ s are also presented by solid triangles to verify the GFS relay forecasts. No error is shown in the occurrence time for the CSV(HRF) second peak intensity (Fig. 12a), but errors in intensity (Fig. 12b), location (Fig. 12c), and hydrological conditions $(P,-\nabla \cdot \mathbf{Q})$ are within the threshold values of the variables considered, as shown in Fig. 5. The successful GFS forecasts for the six $\mathrm{CSV}\left(\mathrm{HRF}^{3}\right)$ second peak intensities offer a feasible way to identify $\operatorname{CSV}\left(\mathrm{HRF}^{3}\right)$ s.

Following step 2 of the forecast advisory, three northeast Asian surface lows, coupled with the coldsurge flows linked to three $\operatorname{CSV}\left(\mathrm{HRF}^{3}\right)$ second peak intensities, developed into NWP explosive cyclones. The occurrence of these explosive cyclones synchronizes with the three $\mathrm{HRF}^{3}$ events.

\section{2) SUFFICIENT REQUIREMENTS}

The following two sufficient requirements must be met to confirm the formation/occurrence of $\mathrm{HRF}^{3}$ events.

(i) Occurrence synchronization of an $H R F^{3}$ cyclonelevent and an NWP explosive cyclone

The deepening rate of six observational explosive cyclones corresponding to the six GFS $\mathrm{HRF}^{3}$ cyclones/events is $\leq-24 \mathrm{hPa} \mathrm{day}^{-1}$ (not shown). In contrast, the six GFS NWP explosive cyclones corresponding to six GFS $\mathrm{HRF}^{3}$ cyclones/events exhibit their deepening rates of surface pressure $\Delta p_{s}^{F}$ around $\leq-15 \mathrm{hPaday}^{-1}$ (Fig. 13a). The occurrence synchronization dates of six GFS HRF cyclones/events and the six GFS NWP explosive cyclones are shown by a diagonal in the scatter diagram for the occurrence dates of the former (ordinate) versus those of the latter (abscissas) shown in Fig. 13b. This sufficient requirement is met by these six GFS HRF cyclones/events.

(ii) Occurrence simultaneity of maximum intensities in three weather systems (HRF ${ }^{3}$ cyclonelevent, tropical trade easterlies during an NP subtropical anticyclone, and NWP explosive cyclone)

In Fig. 9, the maximum intensities for the three weather systems are depicted by $u_{\mathrm{HRF}}^{F}, u_{\mathrm{TTE}}^{F}$, and $u_{\mathrm{PEC}}^{F}$ at $850 \mathrm{hPa}$. The six cases for CSV $\left(\mathrm{HRF}^{3}\right)$ over the 2013-16 period used to verify this forecast advisory belong to two groups:

1) three $\operatorname{CSV}\left(\mathrm{HRF}^{3}\right) \mathrm{s}$ reached their second peak intensity following their formation in 3 days $6 \mathrm{~h}$ and another three $\operatorname{CSV}\left(\mathrm{HRF}^{3}\right)$ s formed in 4 days 6 , while

2) four $\operatorname{CSV}\left(\mathrm{HRF}^{3}\right) \mathrm{s}$ needed 3 days $6 \mathrm{~h}$ from their second peak intensity to form their $\mathrm{HRF}^{3}$ cyclones/events and while another two $\mathrm{CSV}\left(\mathrm{HRF}^{3}\right) \mathrm{s}$ took 4 days $6 \mathrm{~h}$.

The time series for $u_{\mathrm{HRF}}^{F}(850 \mathrm{hPa})$ at the location for this $\mathrm{HRF}^{3}$ cyclone center 5 days prior to and 5 days after the occurrence of $\mathrm{HRF}^{3}$ events for all six cases with the occurrence date of day 0 are shown in Fig. 13c. The forecast time series for $u_{\mathrm{HRF}}^{F}(850 \mathrm{hPa})$ included $u_{\mathrm{HRF}}^{o}(850 \mathrm{hPa})$ before the formation of their parent $\operatorname{CSV}\left(\mathrm{HRF}^{3}\right)$ s. Note that if the GFS formation time for an $\mathrm{HRF}^{3}$ cyclone/event from its parent $\mathrm{CSV}\left(\mathrm{HRF}^{3}\right)$ 


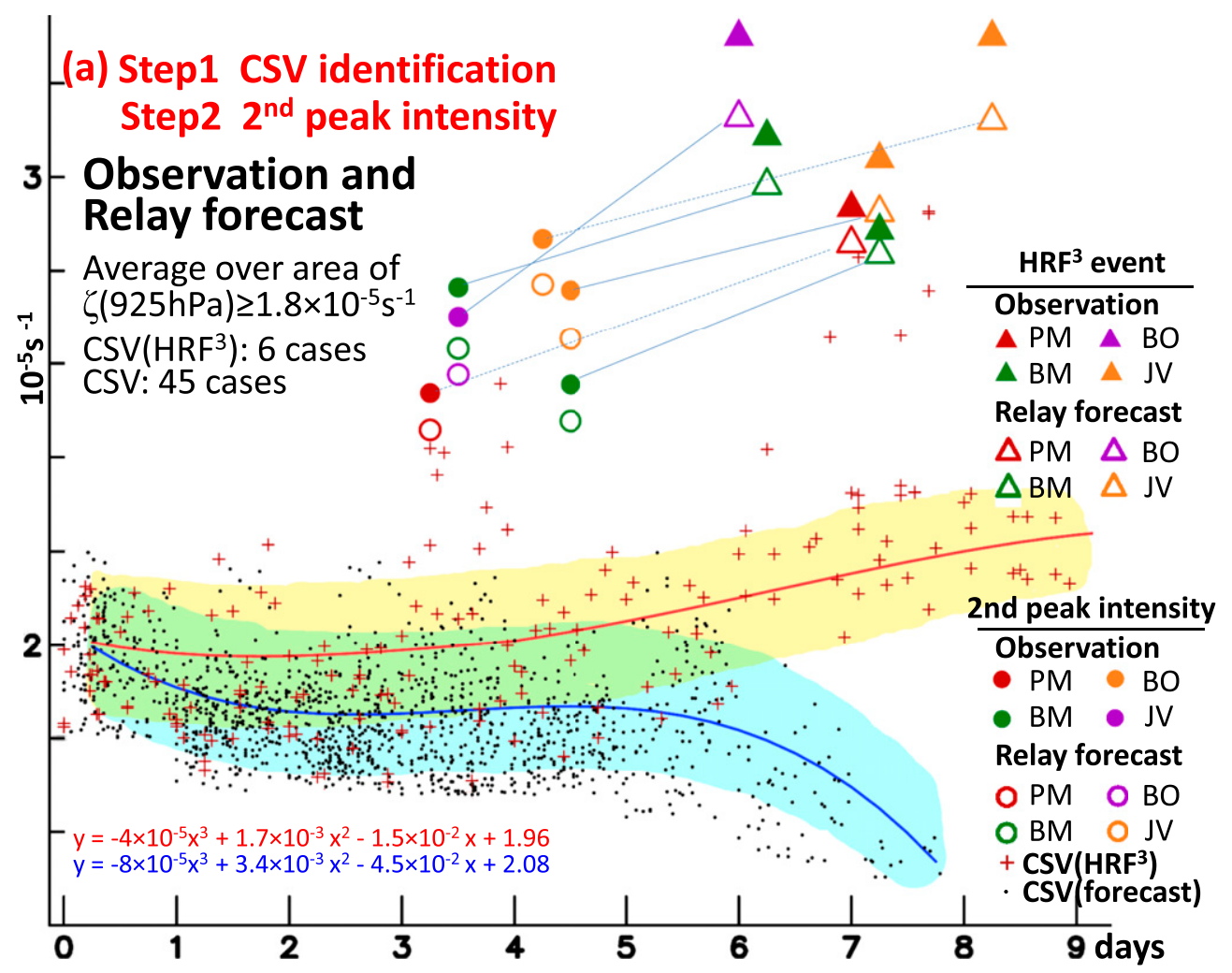

(b) $2^{\text {nd }}$ peak intensity

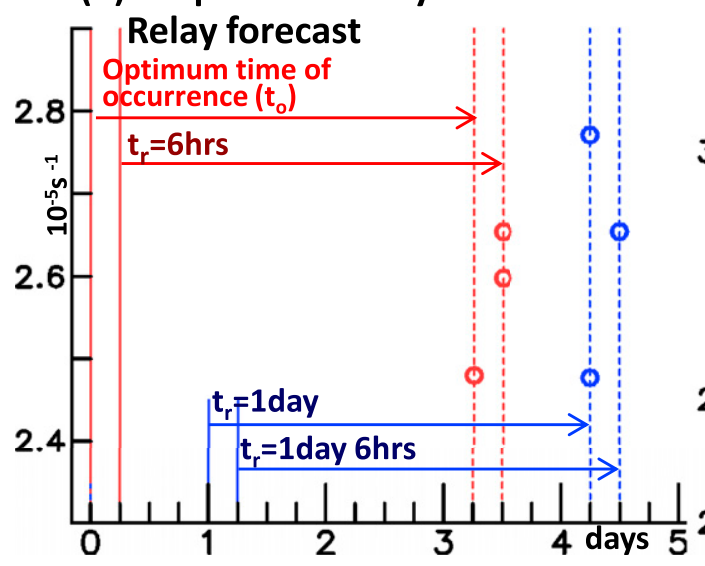
(c) Formation/occurrence of HRF ${ }^{3}$ event

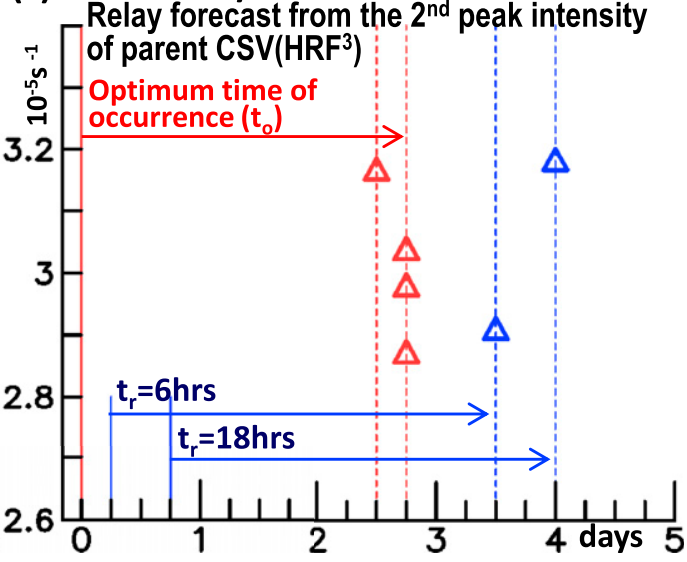

FIG. 11. (a) Temporal evolution of six $\operatorname{CSV}\left(\mathrm{HRF}^{3}\right) \mathrm{s}$ (red crosses) measured with the area-averaged $\zeta(925 \mathrm{hPa})$ with a threshold value $\geq 1.8 \times 10^{-5} \mathrm{~s}^{-1}$ for the three cold seasons of 2013-16 through $t w o$ steps of relay forecasts for the second peak intensity denoted by open circles and for the formation/occurrence of $\mathrm{HRF}^{3}$ events marked by open triangles. To validate these two steps of the relay GFS forecasts, six occurrences of observed $\mathrm{CSV}\left(\mathrm{HRF}^{3}\right)$ second peak intensity and six $\mathrm{HRF}^{3}$ events are shown by six large dots and six solid triangles, respectively. The relay forecasts of $\mathrm{HRF}^{3}$ events (open triangles) are connected with observed $\mathrm{CSV}\left(\mathrm{HRF}^{3}\right)$ second peak intensities of six parent $\operatorname{CSV}\left(\mathrm{HRF}^{3}\right)$ s by thin lines. A third-order polynomial regression line is also added onto the temporal

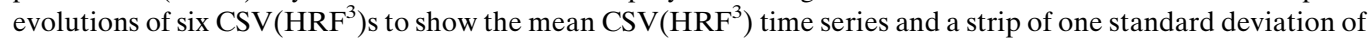
$\mathrm{CSV}\left(\mathrm{HRF}^{3}\right)$ distribution. The temporal evolution of $45 \mathrm{CSVs}$ identified with GFS initial analyses until their demise/disappearance from the GFS forecasts, the third-order polynomial regression line of forecast CSVs, and a standard deviation (light blue strip) with respect to this time series are added on the bottom part of (a) to contrast with (b) the temporal evolutions of GFS CSV $\left(\mathrm{HRF}^{3}\right)$ through their relay forecasts for the second peak intensity of GFS $\mathrm{HRF}^{3}$ and (c) for the formation/occurrence of GFS HRF $\mathrm{HF}^{3}$ events. 
Relay Forecast for

$2^{\text {nd }}$ peak intensity

(a) error: timing (hr)

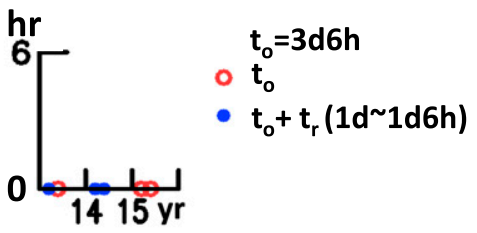

(b) error: intensity

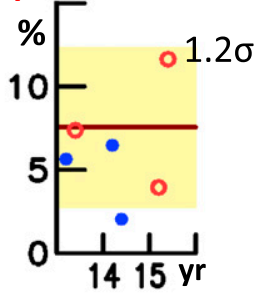

(c) Location error ratio (\%)

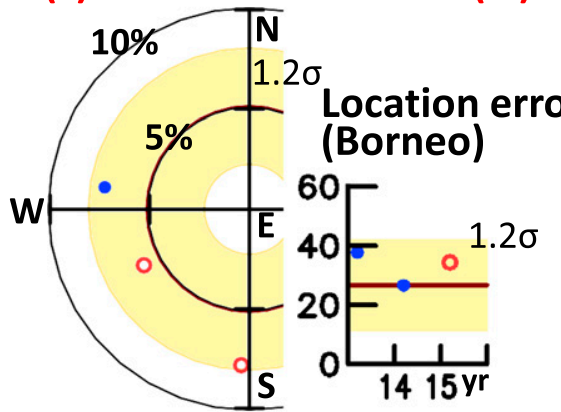

(d) error: Hydrological

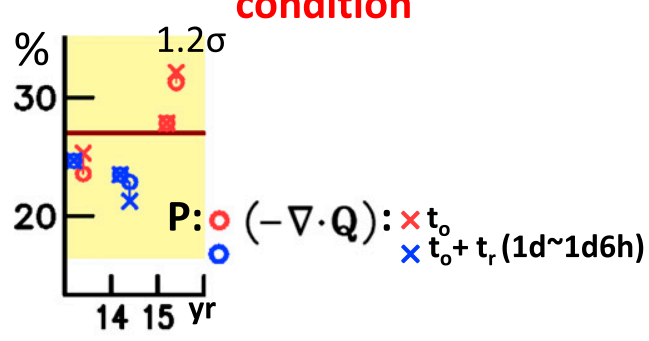

Relay Forecast for $\mathrm{HRF}^{3}$ cyclone/event from its $2^{\text {nd }}$ peak intensity

(e) error: timing ( $\mathrm{hr}$ )

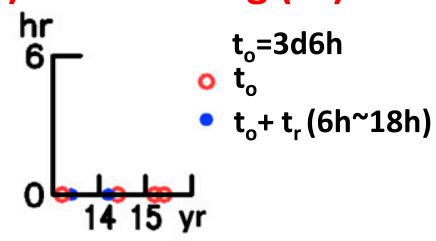

(f) error: intensity

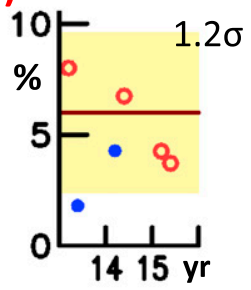

(g) Location error ratio (\%)

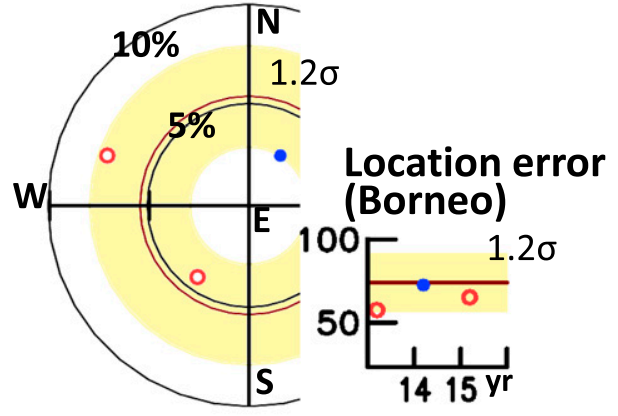

(h) error: Hydrological

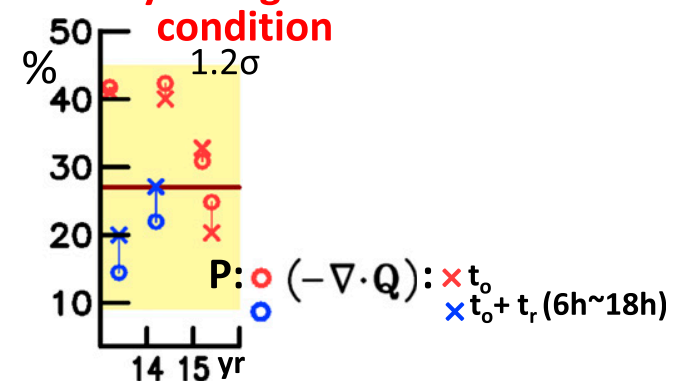

FIG. 12. Bias of relay forecasts for six $\operatorname{CSV}\left(\mathrm{HRF}^{3}\right)$ second peak intensities against observations: errors in (a) occurrence time, (b) intensity [ $\zeta(925 \mathrm{hPa})]$, (c) location, and (d) hydrological condition $(P,-\nabla \cdot \mathbf{Q})$. (e)-(h) As in (a)-(d), but for the bias in the relay forecasts for six $\mathrm{HRF}^{3}$ events from their second peak intensities. A yellow strip of $1.2 \sigma$ ( $\sigma$ shows a standard deviation with respect to the averaged error) for every variable considered is added onto its averaged error.

from its second peak intensity is larger than 3 days $6 \mathrm{~h}$, this extra time is used to delay the GFS forecast for an additional 3 days $6 \mathrm{~h}$. The same procedure is utilized to prepare the time series for $u_{\mathrm{TTE}}^{F}(850 \mathrm{hPa})$ (Fig. 13d) and $u_{\mathrm{PEC}}^{F}(850 \mathrm{hPa})$ (Fig. 13e) at the longitude of the NWP explosive cyclone center. The occurrence simultaneity of the maximum intensities in an $\mathrm{HRF}^{3}$ cyclone/event, the tropical trade easterlies, and the NWP explosive cyclone is also met by the six GFS HRF events. 

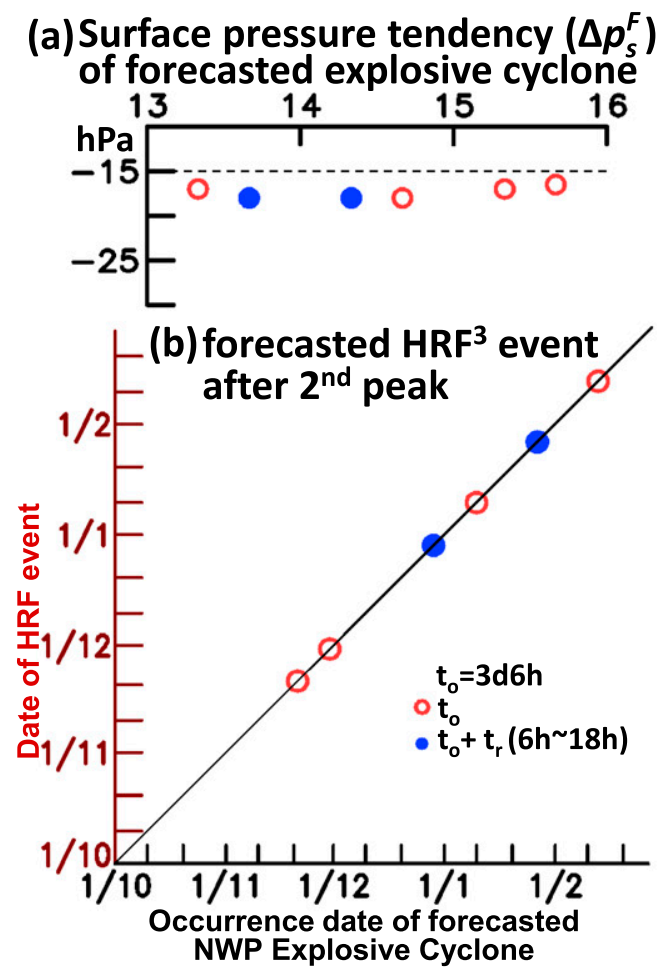

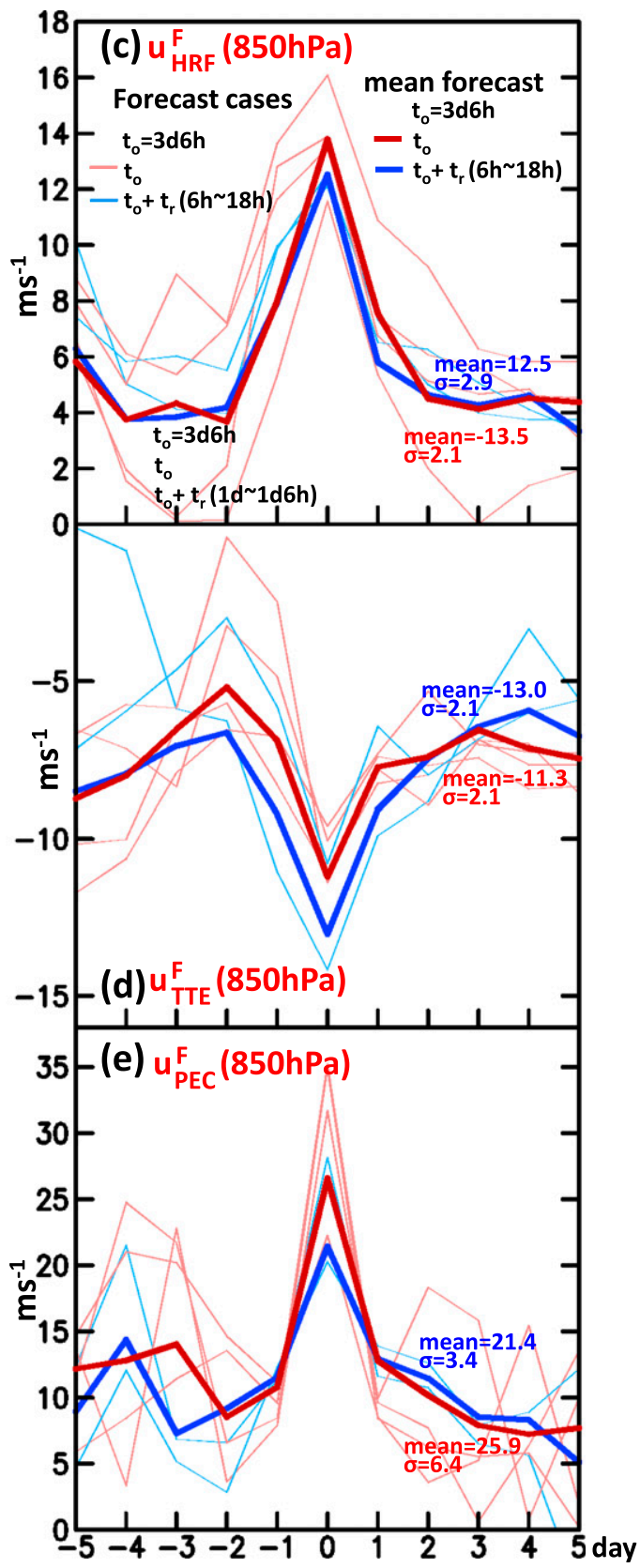

FIG. 13. (a) Surface pressure tendency $\Delta p_{S}^{F}$ of GFS NWP explosive cyclone linked to $H_{R F}^{3}$ events. (b) Scatter diagram for occurrence date of GFS NWP explosive cyclones (ordinate) vs occurrence date of GFS $\mathrm{HRF}^{3}$ events (abscissa). Time series for $u(850 \mathrm{hPa}$ ) at locations of the maximum $850-\mathrm{hPa}$ zonal winds of three weather systems considered: (c) $u_{\mathrm{HRF}}^{F}(850 \mathrm{hPa}),(\mathrm{d}) u_{\mathrm{TTE}}^{F}(850 \mathrm{hPa})$, and (e) $u_{\mathrm{PEC}}^{F}(850 \mathrm{hPa})$, related to the formation/occurrence of six $\mathrm{HRF}^{3}$ events. These GFS $u(850 \mathrm{hPa})$ time series are are depicted by thin blue lines for relay forecasts of four $\mathrm{HRF}^{3}$ events from their second peak intensities and thin red lines for relay forecast of two $\mathrm{HRF}^{3}$ events with a 1-day delay from their second peak intensities. The thick blue (red) line depicts the mean time series for the first (second) group of GFS HRF ${ }^{3}$ events.

Both necessary and sufficient requirements are satisfied by six GFS HRF ${ }^{3}$ events. In addition, despite underforecasted intensities for six GFS $\mathrm{HRF}^{3}$ cyclones (Fig. 11a), errors in their occurrence timing (Fig. 12a) are zero, and errors in their intensity (Fig. 12f), location
(Fig. 12g), and hydrological conditions (Fig. 12h) are all within the threshold values shown in Fig. 7. In conclusion, the proposed forecast advisory works for the formation/ occurrence of $\mathrm{HRF}^{3}$ events from their parent $\mathrm{CSV}\left(\mathrm{HRF}^{3}\right)$ $\mathrm{s}$ over all the cold-season rainfall centers around the SCS. 


\section{Concluding remarks}

The development of CSV(HRF)s from their formation into the formation of HRF events can be classified by the occurrence frequency of their peak intensity doubled or tripled over their life cycles through interactions with cold-surge flows in the SCS. These events are denoted as $\mathrm{HRF}^{2}$ and $\mathrm{HRF}^{3}$ events, respectively. The $\mathrm{CSV}\left(\mathrm{HRF}^{2}\right)$ life cycle necessary to form the $\mathrm{HRF}^{2}$ event is $\leq 5$ days, but to form the $\mathrm{HRF}^{3}$ events the length of time is $\geq 6$ days. The NCEP GFS global forecast outlooks were used to forecast the formation of $\mathrm{HRF}^{2}$ events with the addition of a forecast advisory introduced by Chen et al. (2012) for central Vietnam. Nevertheless, occurrence forecasts for $\mathrm{HRF}^{3}$ events in terms of the GFS after 6 days are still beyond our reach. Chen et al. (2015b) found the $\operatorname{CSV}\left(\mathrm{HRF}^{3}\right)$ development to form $\mathrm{HRF}^{3}$ undergoes triple peak intensities. Making good use of the $\operatorname{CSV}\left(\mathrm{HRF}^{3}\right)$ second peak intensity to forecast the formation/occurrence of $\mathrm{HRF}^{3}$, a forecast advisory was developed with the relay forecast approach for the formation/occurrence of $\mathrm{HRF}^{3}$ events over the entire SCS.

Assessing in terms of the zero-error criteria for the occurrence time of $\mathrm{CSV}\left(\mathrm{HRF}^{3}\right)$ second peak intensity, the optimum forecast time is about 3 days $6 \mathrm{~h}$ (Fig. 4). Based on this special characteristic of $\operatorname{CSV}\left(\mathrm{HRF}^{3}\right)$, a four-step forecast advisory was developed in this study:

1) Step 1-CSVs are identified with the streamline charts prepared with the GFS initial analysis superimposed by $T_{\mathrm{BB}}$ images or rainfall, supplemented with surface analysis maps issued by weather services of countries located throughout the SCS.

2) Step 2-on average, slightly more than $17 \mathrm{CSVs}$ originate in the vicinity of the Philippines and Borneo during the cold season (October-February). In contrast, the occurrence frequency for $\operatorname{CSV}\left(\mathrm{HRF}^{3}\right)$ is $\sim 2.3$. Based on the occurrence optimum time of the $\mathrm{CSV}\left(\mathrm{HRF}^{3}\right)$ second peak intensity from the formation of its parent $\operatorname{CSV}\left(\mathrm{HRF}^{3}\right)$, the GFS forecast can be used to identify the occurrence of the $\operatorname{CSV}\left(\mathrm{HRF}^{3}\right)$ second peak intensity. This special feature of $\operatorname{CSV}\left(\mathrm{HRF}^{3}\right) \mathrm{s}$ is used to separate $\mathrm{CSV}\left(\mathrm{HRF}^{3}\right)$ s from the majority of the CSV population.

3) Step 3: using GFS forecasts, the optimum forecast time for the formation/occurrence of $\mathrm{HRF}^{3}$ events from its second peak intensity is also 3 days $6 \mathrm{~h}$. If this second peak intensity occurs within this optimum time, the GFS forecast at this occurrence time is used to forecast the formation/occurrence of an $\mathrm{HRF}^{3}$ event. If the GFS forecast of the $\operatorname{CSV}\left(\mathrm{HRF}^{3}\right)$ second peak intensity occurs beyond this optimum time, application of the GFS forecast for the $\mathrm{HRF}^{3}$ formation/occurrence is delayed until the occurrence time for this $\operatorname{CSV}\left(\mathrm{HRF}^{3}\right)$ second peak intensity is 3 days $6 \mathrm{~h}$ ahead of the $\mathrm{HRF}^{3}$ occurrence formation.

4) Step 4-the formation/occurrence of an $\mathrm{HRF}^{3}$ event is warranted by satisfying two sufficient requirements: 1) occurrence synchronization of $\mathrm{HRF}^{3}$ events and an NWP explosive cyclone and 2) simultaneous occurrence of the maximum $u_{\mathrm{HRF}}^{F}(850 \mathrm{hPa})$, $u_{\mathrm{TTE}}^{F}(850 \mathrm{hPa})$, and $u_{\mathrm{PEC}}^{F}(850 \mathrm{hPa})$.

The GFS initial analyses and forecasts for three seasons (2013-16) are utilized to perform the verification test of the proposed forecast advisory for the formation/ occurrence of $\mathrm{HRF}^{3}$ events over the cold-season rainfall centers around the SCS.

1) Necessary requirements

Following step 1, 51 CSVs are identified using the GFS initial analyses. The average population of CSVs during the three cold seasons is about $17 \mathrm{CSVs}$ per season, close to the long-term-averaged CSV population ( $\sim 17.2 \mathrm{CSV}$ s per season). Using the GFS forecasts, six $\operatorname{CSV}\left(\mathrm{HRF}^{3}\right) \mathrm{s}$ are identified, as required by step 2 . Three exhibit their second peak intensity at 3 days $6 \mathrm{~h}$ after their parent $\operatorname{CSV}\left(\mathrm{HRF}^{3}\right)$ $\mathrm{s}$ form, but another three form at 4 days $6 \mathrm{~h}$. Thus, three $\operatorname{CSV}\left(\mathrm{HRF}^{3}\right) \mathrm{s}$ are confirmed by the 1-day delay of GFS forecasts.

2) Sufficient requirements

The relay GFS forecasts from the occurrence time of the $\operatorname{CSV}\left(\mathrm{HRF}^{3}\right)$ second peak intensity show that $\mathrm{HRF}^{3}$ events develop from four $\mathrm{CSV}\left(\mathrm{HRF}^{3}\right)$ s within 3 days $6 \mathrm{~h}$, but the other two $\operatorname{CSV}\left(\mathrm{HRF}^{3}\right)$ s need an additional day. The formation forecasts of their $\mathrm{HRF}^{3}$ events are delayed by 1 day. Results from the GFS forecasts show that the occurrence time errors for six $\mathrm{HRF}^{3}$ events are zero, errors for intensity and location are $\leq 10 \%$, and errors for hydrological conditions are $\sim 25 \%$. These errors are within the error threshold values for $35 \mathrm{GFS} \mathrm{HRF}^{3}$ events. The GFS forecasts for six $\mathrm{HRF}^{3}$ events also satisfy both sufficient requirements.

The verification test presented in section $4 \mathrm{~b}$ shows that the proposed forecast advisory for the $\mathrm{HRF}^{3}$ events around the SCS is feasible.

The $\mathrm{HRF}^{2}$ and $\mathrm{HRF}^{3}$ events can be separated by the development times from their parent cold-surge vortices. Using some characteristic differences between CSVs and $\operatorname{CSV}\left(\mathrm{HRF}^{2}\right) \mathrm{s}$, the in-phase occurrence of three monsoon (30-60, 10-20, and 5 day) modes in rainfall and wind speed at the formation/occurrence 
TABLE A1. Explanations of key acronyms used in this study.

\begin{tabular}{|c|c|c|c|}
\hline Acronym & \multicolumn{3}{|c|}{ Definition/expansion } \\
\hline HRF & \multicolumn{3}{|l|}{ Heavy rainfall/flood } \\
\hline CSV & \multicolumn{3}{|c|}{ Cold-surge vortex does not develop into a heavy rainfall/flood event } \\
\hline CSV(HRF) & \multicolumn{3}{|c|}{ Cold-surge vortex develops into a heavy rainfall/flood event } \\
\hline $\mathrm{CSV}\left(\mathrm{HRF}^{2}\right)$ & \multicolumn{3}{|c|}{ CSV(HRF) exhibits peak intensity twice between formation and occurrence of an HRF event } \\
\hline $\mathrm{CSV}\left(\mathrm{HRF}^{3}\right)$ & \multicolumn{3}{|c|}{ CSV(HRF) exhibits peak intensity three times between formation and occurrence of an HRF event } \\
\hline \multirow[t]{2}{*}{$\operatorname{CSV}\left(\mathrm{HRF}^{n}\right) \mathrm{AB}$} & \multicolumn{3}{|c|}{$\mathrm{CSV}\left(\mathrm{HRF}^{n}\right)$ forms in area A and moves to area B where it develops into a heavy rainfall/flood event } \\
\hline & Formation area of $\operatorname{CSV}\left(\mathrm{HRF}^{n}\right)$ & $\frown$ & nce area of an $\mathrm{HRF}^{n}$ event \\
\hline $\mathrm{CV}$ & Philippines and surrounding vicinity & & Vietnam \\
\hline PM & Philippines and surrounding vicinity & & Peninsula \\
\hline BM & Borneo & & Peninsula \\
\hline PS & Philippines and surrounding vicinity & & \\
\hline BS & Borneo & & \\
\hline $\mathrm{BO}$ & Borneo & & \\
\hline JV & Borneo & $\mathrm{Ja}$ & \\
\hline $\mathrm{HRF}^{2}$ & \multicolumn{3}{|c|}{ HRF event occurred at the time of the CSV $\left(H R F^{2}\right)$ 's second intensity peak } \\
\hline $\mathrm{HRF}^{3}$ & \multicolumn{3}{|c|}{ HRF event occurred at the time of the CSV $\left(\mathrm{HRF}^{3}\right)$ 's third intensity peak } \\
\hline $\operatorname{HRF}^{n}(\mathrm{AB})$ & \multicolumn{3}{|c|}{$\begin{array}{l}\text { As explanation of } \operatorname{CSV}\left(\mathrm{HRF}^{n}\right) \mathrm{AB}, \mathrm{A} \text { is the formation area of its parent } \mathrm{CSV}\left(\mathrm{HRF}^{n}\right) \text {, while } \mathrm{B} \text { is the occurrence } \\
\text { area of an } \mathrm{HRF}^{n} \text { event }\end{array}$} \\
\hline NCEP & \multicolumn{3}{|c|}{ National Centers for Environmental Prediction } \\
\hline GFS & \multicolumn{3}{|l|}{ Global Forecast System } \\
\hline NWP & \multicolumn{3}{|l|}{ Northwest Pacific } \\
\hline NP & \multicolumn{3}{|l|}{ North Pacific } \\
\hline$\Delta p_{s}^{o}\left(\Delta p_{s}^{F}\right)$ & \multicolumn{3}{|c|}{ Observed (forecasted) surface pressure tendency } \\
\hline$u_{\mathrm{HRF}}^{o}\left(u_{\mathrm{HRF}}^{F}\right)$ & \multicolumn{3}{|c|}{ Observed (forecasted) max westerlies of an HRF cyclone/event } \\
\hline$u_{\mathrm{TTE}}^{o}\left(u_{\mathrm{TTE}}^{F}\right)$ & \multicolumn{3}{|c|}{ Observed (forecasted) max tropical trade easterlies } \\
\hline$u_{\mathrm{PEC}}^{o}\left(u_{\mathrm{PEC}}^{F}\right)$ & \multicolumn{3}{|c|}{ Observed (forecasted) max westerlies of an NWP explosive cyclone } \\
\hline
\end{tabular}

time of an HRF event, the occurrence synchronization of an HRF cyclone/event and NWP explosive cyclone, and the simultaneity occurrence of maximum $u_{\mathrm{HRF}}^{F}$, $u_{\mathrm{TTE}}^{F}$, and $u_{\mathrm{PEC}}^{F}$, Chen et al. (2012) introduced a forecast advisory for the formation/occurrence of $\mathrm{HRF}^{2}$ events in central Vietnam. In the present study, a forecast advisory for the formation/occurrence of $\mathrm{HRF}^{3}$ events is developed from the utilization of the relay GFS forecasts for the occurrence of the $\mathrm{CSV}\left(\mathrm{HRF}^{3}\right)$ second peak intensity and the relay GFS forecasts for the formation/ occurrence of $\mathrm{HRF}^{3}$ events from the second peak intensity of their parent $\mathrm{CSV}\left(\mathrm{HRF}^{3}\right) \mathrm{s}$. After the development/formation mechanisms for both $\mathrm{HRF}^{2}$ and $\mathrm{HRF}^{3}$ events around the SCS were disclosed by Chen et al. (2015a,b), forecasts for the occurrences of both $\mathrm{HRF}^{2}$ and $\mathrm{HRF}^{3}$ events around the SCS with the NCEP GFS forecasts can be feasibly performed with the combination of both forecast advisories by Chen et al. (2012) and this present study.

Acknowledgments. The Cheney Research Fund and NSF Grant ATM-0136220 sponsored this study. JM's contribution to this study is supported by the JSPS KAKENHI (Grant 26220202) and the Grant-in-Aid for Research on Priority Areas and the Leading Project of Tokyo Metropolitan University, Japan. Comments/ suggestions offered by anonymous reviewers were helpful in improving this paper.

\section{APPENDIX}

\section{Explanation of Key Acronyms Used in This Study}

The acronyms used in this study are explained in Table A1.

\section{REFERENCES}

Ashouri, H., K.-L. Hsu, S. Sorooshian, D. K. Braithwaite, K. R. Knapp, L. D. Cecil, B. R. Nelson, and O. P. Prat, 2015: PERSIANN-CDR: Daily precipitation climate data record from multisatellite observations for hydrological and climate studies. Bull. Amer. Meteor. Soc., 96, 69-83, doi:10.1175/ BAMS-D-13-00068.1.

BBC, 2008: Floods kill 49 people in Vietnam. [Available online at http://news.bbc.co.uk/2/hi/asia-pacific/7703672.stm.]

Blersch, D. J., and T. C. Probert, 1991: Geostationary meteorological satellite systems-An overview. J. Pract. Appl. Space, 2, 1-13.

Chen, T.-C., M.-C. Yen, J.-D. Tsay, J. Alpert, and N. T. T. Thanh, 2012: Forecast advisory for the late fall heavy rainfall/flood event in central Vietnam developed from diagnostic analysis. Wea. Forecasting, 27, 1155-1177, doi:10.1175/WAF-D-11-00104.1. 
J.-D. Tsay, M.-C. Yen, and J. Matsumoto, 2013a: Interannual variation of the winter rainfall in Malaysia. J. Climate, 26, 4630-4648, doi:10.1175/JCLI-D-12-00367.1.

,,--- , and $-2013 \mathrm{~b}$ : The winter rainfall of Malaysia. J. Climate, 26, 936-958, doi:10.1175/JCLI-D-12-00174.1.

— - _ and J. Matsumoto, 2015a: Development and formation mechanism of the Southeast Asian winter heavy rainfall events around the South China Sea. Part II: Formation of heavy rainfall events. J. Climate, 28, 1444-1464, doi:10.1175/ JCLI-D-14-00171.1.

$\longrightarrow, \ldots, \ldots$, and J. Alpert, 2015b: Development and formation mechanism of the Southeast Asian winter heavy rainfall events around the South China Sea. Part I: Formation and propagation of cold surge vortex. J. Climate, 28, 1417-1443, doi:10.1175/JCLI-D-14-00170.1.

Cotton, W. R., and Coauthors, 2003: RAMS 2001: Current status and future directions. Meteor. Atmos. Phys., 82, 5-29, doi:10.1007/s00703-001-0584-9.

CRED, 2016: EM-DAT: The International Disaster Database. Center for Research on the Epidemiology of Disasters. [Available online at http://www.emdat.be/.]

Dee, D. P., and Coauthors, 2011: The ERA-Interim reanalysis: Configuration and performance of the data assimilation system. Quart. J. Roy. Meteor. Soc., 137, 553-597, doi:10.1002/ qj.828.

DFO, 2016: Global Active Archive of Large Flood Events. Dartmouth Flood Observatory. [Available online at http:// floodobservatory.colorado.edu/.]

Huffman, G. J., and D. T. Bolvin, 2015: Real-Time TRMM MultiSatellite Precipitation Analysis data set documentation. NASA Goddard Space Flight Center, 48 pp. [Available online at ftp://trmmopen.gsfc.nasa.gov/pub/merged/V7Documents/ 3B4XRT_doc_V7.pdf.]

Juneng, L., F. T. Tangang, and C. J. C. Reason, 2007: Numerical case study of an extreme rainfall event during 9-11 December 2004 over the east coast of Peninsular Malaysia. Meteor. Atmos. Phys., 98, 81-98, doi:10.1007/s00703-006-0236-1.

Maisarah, W., W. Ibadullah, M. K. Sammathuria, and L. L. Kwok, 2013: Comparison of performance of NWP models WRFV2.2 and WRFV3.4 during a heavy rainfall episode in northeast monsoon season 2011. Malaysia Meteorological Department Research Publ. 5/2013, 15 pp. [Available online at http://www.met.gov.my/web/metmalaysia/publications/ technicalpaper/fullpapers/document/44755/rp05_2013.pdf.]

MSC, 1997: GMS-5 user's guide. 3rd ed. Meteorological Satellite Center, Tokyo, Japan, 190 pp.

NCAR, 2016: Regression \& trend: Decadal trend of IPO and global mean (8-yr): NCAR Command Language (version 6.3.0). UCAR/NCAR/CISL/TDD. [Available online at http://www. ncl.ucar.edu/Applications/regress.shtml.]

NCEI, 2016: Service Records Retention System Analysis. National Centers for Environmental Information. [Available online at http://nomads.ncdc.noaa.gov/ncep/NCEP.]

NCEP, 2003: The GFS atmospheric model. NCEP Office Note 442, 14 pp. [Available online at http://nws.noaa.gov/ost/climate/ STIP/AGFS_DOC_1103.pdf.]

NWS/EMC, 2016: The Global Forecast System (GFS)—Global Spectral Model (GSM) (GSM version 13.0.2). NWS/Environmental Modeling Center. [Available online at http://www.emc.ncep. noaa.gov/GFS/doc.php.]

Reliefweb, 2009: More than 16,000 evacuated as Malaysian floods worsen. [Available online at http://reliefweb.int/node/334708.]

Saito, K., and Coauthors, 2012: International research for prevention and mitigation of meteorological disasters in Southeast Asia. Meteorological Research Institute Tech. Rep. 65, 209 pp. [Available online at http://www.mri-jma.go.jp/Publish/ Technical/DATA/VOL_65/tec_rep_mri_65.pdf.]

Sanders, F., and J. R. Gyakum, 1980: Synoptic-dynamic climatology of the "bomb." Mon. Wea. Rev., 108, 1589-1606, doi:10.1175/ 1520-0493(1980)108<1589:SDCOT>2.0.CO;2.

Truong, N. M., T. T. Tien, R. A. Pielke Sr., C. L. Castro, and G. Leoncini, 2009: A modified Kain-Fritsch scheme and its application for the simulation of an extreme precipitation event in Vietnam. Mon. Wea. Rev., 137, 766-789, doi:10.1175/ 2008MWR2434.1.

UNISDR, 2013: Strengthening of hydrometeorological services in Southeast Asia: Country assessment report for Viet Nam. U.N. International Strategy for Disaster Reduction, $96 \mathrm{pp}$. [Available online at http://www.unisdr.org/we/inform/publications/33988.]

Yatagai, A., K. Kamiguchi, O. Arakawa, A. Hamada, N. Yasutomi, and A. Kitoh, 2012: APHRODITE: Constructing a long-term daily gridded precipitation dataset for Asia based on a dense network of rain gauges. Bull. Amer. Meteor. Soc., 93, 14011415, doi:10.1175/BAMS-D-11-00122.1. 